\title{
Cytokine secretion requires phosphatidylcholine synthesis
}

\author{
Yong Tian, ${ }^{1}$ Caroline Pate, ${ }^{1}$ Alberto Andreolotti, ${ }^{1,3}$ Limin Wang, ${ }^{1}$ Elaine Tuomanen, ${ }^{1}$ Kelli Boyd, ${ }^{2}$ Enrique Claro, ${ }^{3}$ \\ and Suzanne Jackowski ${ }^{1}$ \\ 'Department of Infectious Diseases and ${ }^{2}$ Animal Resource Center, St. Jude Children's Research Hospital, Memphis, TN 38105 \\ ${ }_{3}^{3}$ Institut de Neurociències i Departament de Bioquímica i Biologia Molecular, Universitat Autònoma de Barcelona, E-08 193 Bellaterra, Spain
}

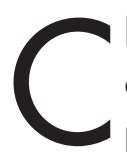
holine cytidylyltransferase (CCT) is the rate-limiting enzyme in the phosphatidylcholine biosynthetic pathway. Here, we demonstrate that $\mathrm{CCT} \alpha$-mediated phosphatidylcholine synthesis is required to maintain normal Golgi structure and function as well as cytokine secretion from the Golgi complex. CCT $\alpha$ is localized to the trans-Golgi region and its expression is increased in lipopolysaccharide (LPS)-stimulated wild-type macrophages. Although LPS triggers transient reorganization of Golgi morphology in wild-type macrophages, similar structural alterations persist in $\mathrm{CCT}_{\alpha}$-deficient cells. Pro-tumor necrosis

\section{Introduction}

Membrane biogenesis is dependent on phospholipid synthesis, specifically phosphatidylcholine (PtdCho), the most abundant phospholipid component that forms the bilayer barrier structure in eukaryotic cells. Doubling of the membrane phospholipid during cell cycle progression is regulated in part by the phosphocholine cytidylyltransferase (CCT; Jackowski, 1994, 1996), a key enzyme in PtdCho synthesis (Jackowski and Fagone, 2005). Also, biochemical activation of CCT mediates expansion of the ER membrane in B lymphocytes that are activated by

Y. Tian and C. Pate contributed equally to this paper.

Correspondence to Suzanne Jackowski: suzanne.jackowski@stjude.org

L. Wang's present address is Department of Internal Medicine, University of California, Davis, Davis, CA 95616.

Abbreviations used in this paper: ApoE, apolipoprotein $\mathrm{E}$; CCT, cytidylyltransferase; CDP-Cho, cytidine diphosphocholine; C/EPT, choline/ethanolamine phosphotransferase; CPT, choline phosphotransferase; ERGIC-53, ER-Golgi intermediate compartment 53-kD protein; edelfosine, Et-18-OCH $3 ; \mathrm{FMLP}$, formyl-methionylleucylphenylalanine; GAPDH, glyceraldehyde-3-phosphate dehydrogenase; IL-1 $\beta$, interleukin-1 $\beta$; IL-6, interleukin-6; LCM, L cell-conditioned medium; LPS, lipopolysaccharide; lysoPC, lysophosphatidylcholine; PEMT, phosphatidylethanolamine methyltransferase; $\mathrm{PGE}_{2}$, prostaglandin $\mathrm{E}_{2} ; \mathrm{PLD} 1$, phospholipase D1; pro-TNF $\alpha$, precursor form of TNF $\alpha$; PtdCho, phosphatidylcholine; PtdEtn, phosphatidylethanolamine; $\mathrm{PtdOH}$, phosphatidic acid; P'tse, phosphatase; qRT-PCR, quantitative RT-PCR; SM, sphingomyelin; TAPI, N-(D,L-[2(hydroxyaminocarbonyl)methyl]-4-methylpentanoyl)---3-(2'naphthyl)-alanyl-t-alanine, 2-aminoethylamide; TACE, TNF $\alpha$-converting enzyme.

The online version of this paper contains supplemental material. factor $\alpha$ and interleukin- 6 remain lodged in the secretory compartment of $\mathrm{CCT}_{\alpha}$-deficient macrophages after LPS stimulation. However, the lysosomal-mediated secretion pathways for interleukin-1 $\beta$ secretion and constitutive apolipoprotein E secretion are unaltered. Exogenous lysophosphatidylcholine restores LPS-stimulated secretion from CCT $\alpha$-deficient cells, and elevated diacylglycerol levels alone do not impede secretion of pro-tumor necrosis factor $\alpha$ or interleukin-6. These results identify CCT $\alpha$ as a key component in membrane biogenesis during LPS-stimulated cytokine secretion from the Golgi complex. lipopolysaccharide (LPS; Fagone et al., 2007). Inactivation of CCT either genetically or pharmacologically in immortalized cells leads to cell death (Lykidis and Jackowski, 2001; Cui and Houweling, 2002). Genetic deletion in mice of the ubiquitous $\mathrm{CCT} \alpha$ isoform is lethal in embryogenesis before the blastocyst stage (Wang et al., 2005). These results and the fact that the $\mathrm{CCT} \alpha$ isoform is expressed at levels 10- to 30-fold higher than the $\beta$ isoforms (Jackowski et al., 2004) suggest that CCT $\alpha$ activity is required to support membrane biogenesis. However, tissuespecific deletion of $\mathrm{CCT} \alpha$ in mice does not severely restrict the proliferation or development of mouse macrophages (Zhang et al., 2000), hepatocytes (Jacobs et al., 2004), or lung epithelial cells (Tian et al., 2007), which demonstrates that either expression of the ССТ $\beta 2$ or СCT $\beta 3$ isoforms in mice (Karim et al., 2003) is sufficient for development and differentiation, and/or that circulating lipoproteins supply substantial amounts of PtdCho to primary cells and tissues (Gunter et al., 2007). However, the loss of CCT $\alpha$ expression does alter the differentiated function of these cell types. CCT $\alpha$-deficient macrophages have increased susceptibility to cell death by apoptosis after challenge with cholesterol (Zhang et al., 2000; Devries-Seimon et al., 2005). Deficient hepatocytes are larger, and secretion of high-density lipoprotein and very low-density lipoprotein from the liver is impaired (Jacobs et al., 2004). Conditional deletion 
Figure 1. Reduced PtdCho synthesis in CCT $\alpha$ deficient macrophages. (A) Wild-type (WT; $n=12$ ) or CCT $\alpha$-deficient (KO; $n=12$ ) macrophages were labeled for $6 \mathrm{~h}$ with $1 \mu \mathrm{Ci} / \mathrm{m}$ $\left[{ }^{3} \mathrm{H}\right]$ choline, and incorporation into PtdCho was normalized to cellular protein. (B) Relative transcript levels for $\mathrm{CCT} \alpha, \mathrm{CCT} \beta 2$, ССT $\beta 3$, or PEMT were determined by real-time qRT-PCR in wild-type $(n=3)$ or CCT $\alpha$-deficient $(n=3)$ macrophages. (C) CCT enzyme activity in wildtype $(O ; n=4)$ or CCT $\alpha$-deficient $(\mathbf{O} ; n=4)$ macrophage lysates was determined in vitro as a function of protein concentration. (D) Protein expression levels of CCT $\alpha(42 \mathrm{kD})$ and CCT $\beta 3$ (39 kD) were determined in wild-type and CCT $\alpha$-deficient macrophage lysates $(50 \mu \mathrm{g})$ by immunoblotting with isoform-specific antibodies. Immunoblots are representative of macrophages from two mice of each genotype. Cells (HEK293T) transfected with expression plasmids encoding CCT $\alpha$ or CCT $\beta 3$ were lysed, and $5 \mu \mathrm{g}$ of protein was loaded as a positive control. Multiple immunopositive bands in a lane correspond to different phosphorylation states of the CCT protein (Jackowski, 1994; Lykidis et al., 1998) Error bars indicate mean $\pm \mathrm{SE} .{ }^{*}, \mathrm{P}<0.05$; $* *, P<0.01$
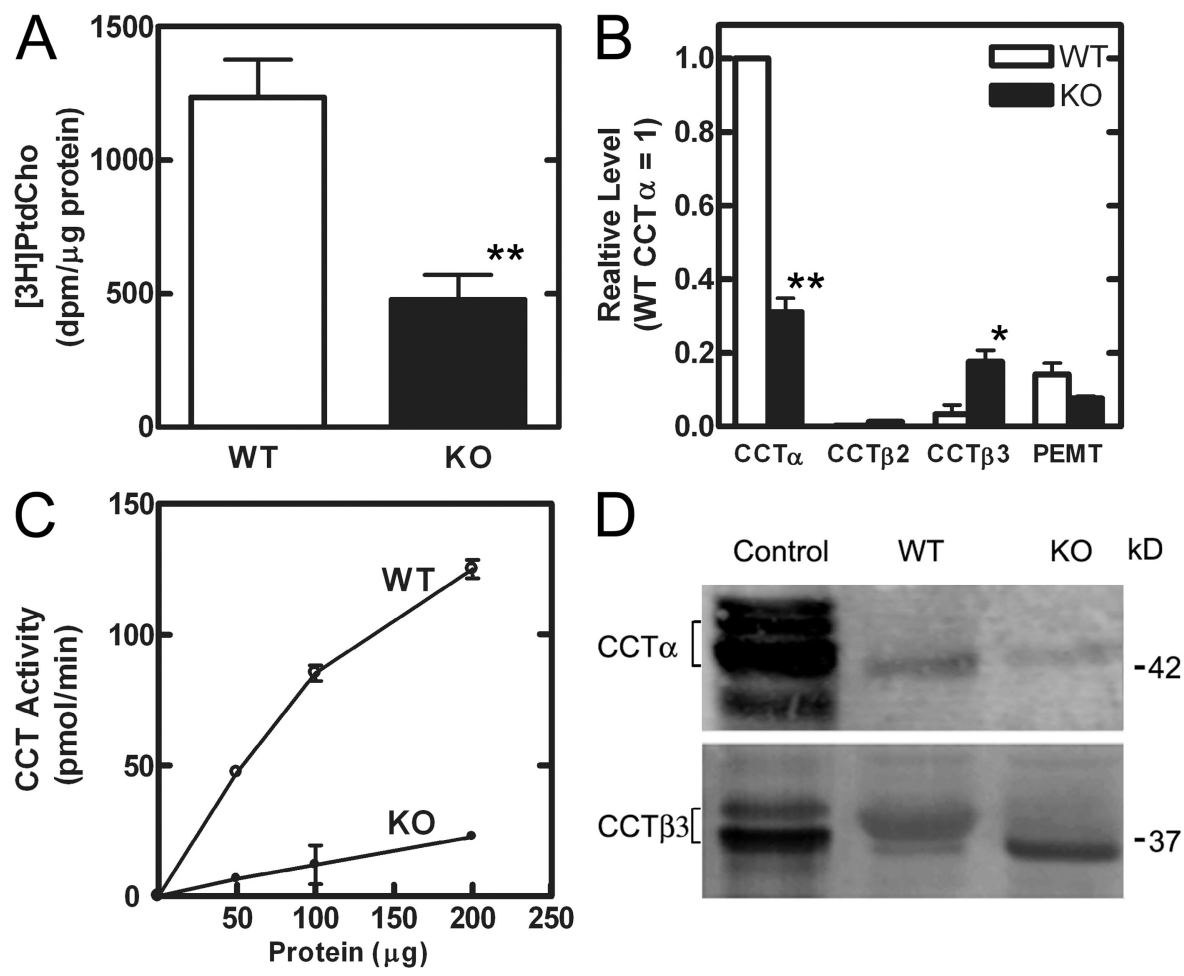

of CCT $\alpha$ in lung epithelia results in insufficient synthesis and secretion of dipalmitoyl-PtdCho, the major surfactant phospholipid (Tian et al., 2007). These data obtained by inactivation of CCT $\alpha$ in selected primary cells argue for specific roles for PtdCho synthesis in supporting the function rather than the formation of differentiated cells.

Macrophages are multitalented cells in natural host defense that are activated to protect against a wide variety of invading microorganisms. The cells also have extensive biosynthetic capabilities that result in the secretion of complement components, cytokines, prostaglandins, and numerous other biologically active factors that modulate the activities of other lymphoreticular cells. Many macrophage functions, including phagocytosis and secretion, involve membrane reconfiguration and movement, and are often accompanied by remodeling of the membrane lipids. For example, the phospholipase D1 (PLD1; Iyer et al., 2004; Corrotte et al., 2006) converts the PtdCho into phosphatidic acid (PtdOH), cytoplasmic phospholipase $\mathrm{A}_{2}$ is recruited to the phagosome (Girotti et al., 2004) to release arachidonic acid, an eicosanoid precursor, and the phosphorylated inositol phospholipids undergo localized changes during phagosome formation (Lindmo and Stenmark, 2006; Yeung et al., 2006). The generation of polyphosphoinositides, DAG, and PtdOH regulate secretion events (Roth, 1999; Huijbregts et al., 2000; Freyberg et al., 2003; Wenk and De, 2004; Munro, 2005; Lev, 2006) by recruiting cytoplasmic proteins to the Golgi apparatus or secretory vesicles to modify the membrane or couple with effector molecules. These localized changes in lipid composition signal trafficking proteins and also influence membrane organization and properties, thus promoting membrane fission or fusion (Weigert et al., 1999; Shemesh et al., 2003; Corda et al., 2006; Carrasco and Merida, 2007).
In proliferating cells, the ER is a major site of PtdCho synthesis (Henneberry et al., 2002; Fagone et al., 2007; Sriburi et al., 2007), and PtdCho is then mobilized to the Golgi compartment (Altan-Bonnet et al., 2004, 2006). DAG production is initiated by the breakdown of PtdCho by phospholipase D followed by a PtdOH phosphatase (P'tse), and this process promotes secretion through the Golgi apparatus (Kearns et al., 1997; Litvak et al., 2005; Lev, 2006). Maintaining the supply of DAG is critical to secretion in both yeast and mammalian cells, and the inhibition of PtdCho synthesis increases DAG (Kearns et al., 1997; Litvak et al., 2005). DAG is reincorporated into PtdCho by choline phosphotransferase (CPT) activity located at the Golgi apparatus (Henneberry et al., 2002; Gilchrist et al., 2006), but the limiting substrate for this reaction is cytidine diphosphocholine (CDP-Cho) produced by CCT (Jackowski and Fagone, 2005). In this study, we find that genetic inactivation of the major CCT isoform in murine macrophages resulted in reduced PtdCho synthesis and increased DAG levels, coupled with impaired secretion of cytokines from the Golgi apparatus of stimulated cells. The experiments illustrate that PtdCho biosynthesis is critical for vesicular traffic from the Golgi apparatus and that aberrantly high DAG levels do not impede vesicular transport.

\section{Results}

Mice with $\mathrm{CCT} \alpha$-null macrophages were derived as described previously (Zhang et al., 2000). In brief, mice carrying a floxed Pcytla gene were crossed with mice carrying a Cre recombinase driven by the macrophage-specific LysM promoter. Two flox sites flanked a $12.5-\mathrm{kb}$ fragment of the Pcytla gene containing exons 5-9 (Karim et al., 2003) and the intervening introns. Deletion of the region between the flox sites resulted in expression of a 
truncated $\mathrm{CCT} \alpha$ protein that lacked the catalytic and regulatory domains located at the carboxy terminus. Mice that were homozygous for the floxed gene and heterozygous for the LysMCre gene were mated, and the pups were genotyped and used to obtain either CCT $\alpha$ knockout or littermate wild-type control macrophages. Peritoneal macrophages were elicited, and the $\mathrm{CCT} \alpha$-deficient macrophage population was confirmed to have reduced rates of de novo PtdCho synthesis as measured by $\left[{ }^{3} \mathrm{H}\right]$ choline incorporation into the lipid fraction of adherent cells (Fig. 1 A). The deletion in this macrophage model was not completely penetrant (Zhang et al., 2000). Analysis of the CCT $\alpha$ transcript level in CCT $\alpha-$ deficient macrophages by quantitative RT-PCR (qRT-PCR) revealed that the transcript level was significantly reduced to $30 \%$ of the wild-type level (Fig. 1 B). The CCT $\alpha$-null cells were $\geq 95 \%$ macrophages as determined microscopically after staining with macrophage-specific anti-mouse CD11b. Cells were also stained for expression of CCT $\alpha$ protein, and $20-30 \%$ of the macrophages isolated from individual knockout mice $(n=4)$ remained positive for expression, which confirms that the action of the Cre recombinase was not $100 \%$ penetrant. Thus, the residual PtdCho synthesis measured by metabolic radiolabeling in the CCT $\alpha$-null populations was due not only to expression of the alternate isoform, CCT $\beta 3$ (Fig. 1 B), but also to the presence of cells that did not delete the CCT $\alpha$ gene. The qRT-PCR revealed that the CCT $\beta 2$ isoform was not expressed in macrophages, and that CCT $\beta 3$ expression was increased in the knockouts. СCT $\beta 3$ is equivalent to $\mathrm{CCT} \alpha$ in its primary biochemical function, and expression of its activity can compensate for loss of CCT $\alpha$ to support bulk membrane synthesis in cultured cells (Karim et al., 2003). It was previously found that CCT $\beta 2$ expression increased in the CCT $\alpha$-deficient cells (Zhang et al., 2000), but at the time, ССТ $\beta 3$ had not been discovered, and both isoforms share the common epitope that was signaled in the previous immunoblots (Karim et al., 2003). Total CCT activity was significantly lower in cell lysates prepared from $\mathrm{CCT} \alpha$-null macrophages compared with wild-type populations (Fig. $1 \mathrm{C}$ ), and these data agreed with the previously published study (Zhang et al., 2000). The decrease in CCT $\alpha$ and the increase in CCT 33 protein assessed by immunoblotting with isoformspecific antibodies reflected the changes in mRNA levels (Fig. 1 D). Macrophages were isolated from two knockout and two wild-type mice and pooled according to genotype, then immunoblots were prepared from six replicates of each genotype. The level of CCT $\alpha$ protein in the knockout population was $0.36 \pm 0.08$ compared with the wild-type population (level set at 1.00). The reduction in CCT $\alpha$ transcripts correlated with the protein level determined by immunoblots and with the number of macrophages devoid of $\mathrm{CCT} \alpha$ expression as determined by microscopy of immunostained cell populations. These data confirm the loss of CCT $\alpha$ expression in the majority of cells and also provide the first example of CCT $\beta 3$ regulation as an adaptive response to PtdCho deficiency.

Several macrophage functions were assessed to determine if they were compromised by reduced PtdCho synthesis. Phagocytosis was evaluated by quantifying the uptake of fluoresceinlabeled Escherichia coli, and the values were normalized to cell number by counterstaining and measuring DAPI fluorescence. The uptake of the bacteria was linear up to $2 \mathrm{~h}$ and was the same in both wild-type and CCT $\alpha$-deficient cells (Fig. 2 A). Random
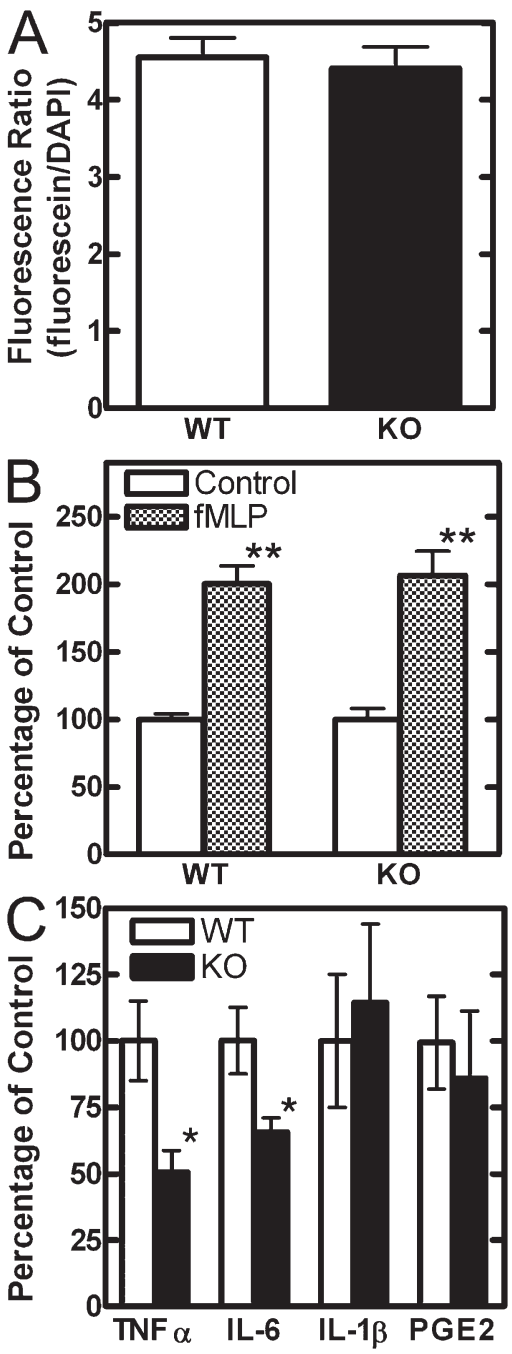

Figure 2. Functional comparison of wild-type and CCT $\alpha$-deficient macrophages. (A) Phagocytosis of fluorescein-labeled $E$. coli was quantified after $2 \mathrm{~h}$ of incubation and then normalized to the cell number by staining with DAPI as described in Materials and methods $(n=8)$. (B) Chemotaxis was measured by migration of wild-type (WT; $n=8$ ) or CCT $\alpha$-deficient (KO; $n=16$ ) macrophages in modified Boyden chambers after $4 \mathrm{~h}$ of incubation with either LCM or LCM plus n-fMLP. The numbers of cells in the target chambers were determined by staining with Calcein $A M$, quantification of the fluorescent signal, and comparison with a calibration curve of increasing cell number. (C) Cytokine and $\mathrm{PGE}_{2}$ secretion from wild-type (white; $n=8$ ) and CCT $\alpha$-deficient (black; $n=8$ ) macrophages $18 \mathrm{~h}$ after LPS stimulation was measured with the Luminex assay (BioRad Laboratories) or by individual ELISA assays and normalized to protein content in each sample. The mean values for cytokines in the medium from WT cells were: $\mathrm{TNF} \alpha, 319.3 \mathrm{pg} / \mu \mathrm{g}$ cell protein; IL-6, $266.2 \mathrm{pg} / \mu \mathrm{g}$ cell protein; IL-1 $\beta$, $15.3 \mathrm{pg} / \mu \mathrm{g}$ cell protein; and $\mathrm{PGE}_{2}, 5.46 \mathrm{pg} / \mu \mathrm{g}$ cell protein. Error bars indicate mean $\pm \mathrm{SE} .{ }^{*}, \mathrm{P}<0.05 ;{ }^{*}, \mathrm{P}<0.01$.

migration and chemotaxis of the macrophages in response to the attractant formyl-methionylleucylphenylalanine (fMLP) was determined in modified Boyden chambers. The numbers of cells that crossed a membrane into an adjacent chamber containing medium alone or medium plus $10 \mathrm{nM}$ fMLP were determined by staining with Calcein AM, and the data were normalized to the starting cell number. The assay was linear for at least $4 \mathrm{~h}$ and both the knockout and wild-type cell populations exhibited similar rates of random migration and chemotaxis (Fig. 2 B). Cytokine production by macrophages in response to E. coli LPS 

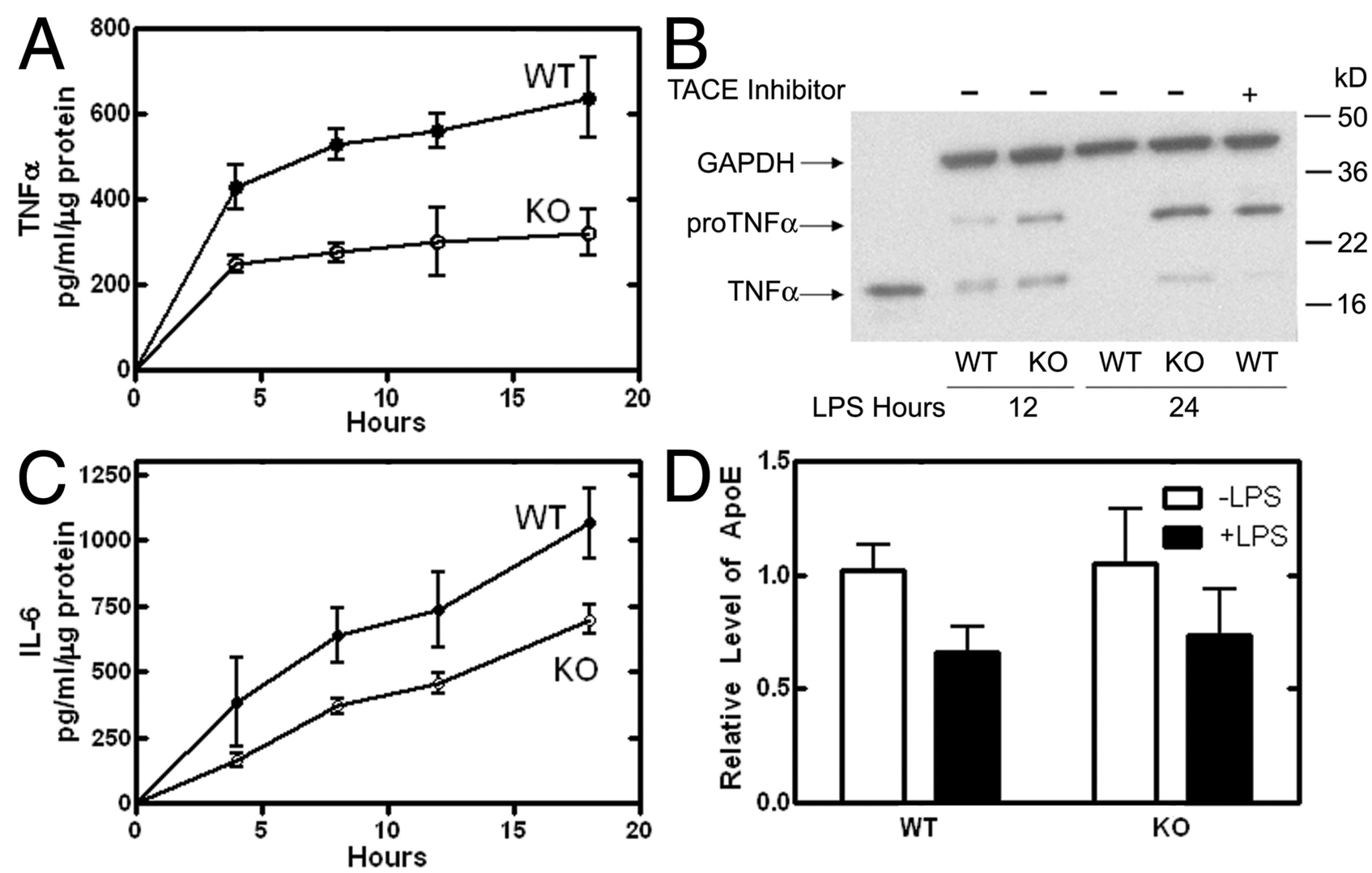

Figure 3. Secretion and processing of TNF $\alpha$. (A) TNF $\alpha$ in the culture medium from wild-type $(O ; n=5)$ or CCT $\alpha$-deficient $(\mathbf{0} ; n=10)$ macrophages was measured at indicated times after LPS stimulation. The anti-TNF $\alpha$ antibody used in the ELISA recognized both the pro-TNF $\alpha$ and mature TNF $\alpha$. (B) Synthesis and processing of TNF $\alpha$ was evaluated by immunoblotting cell lysates from wild-type (WT) or CCT $\alpha$-deficient (KO) macrophages. Cells were treated with LPS for either 12 or $24 \mathrm{~h}$, or with an inhibitor of TACE, TAPI, which was added to selected cultures to confirm the identification of the unprocessed pro-TNF $\alpha$. Purified recombinant mouse TNF $\alpha$ (Leinco Technologies, Inc.) was a positive control (lane 1), and anti-GAPDH mAb (Ambion) was used to confirm equal protein loading $(50 \mu \mathrm{g})$ in each lane. The data are representative of three independent experiments. (C) IL-6 in the culture medium from the same macrophages used in A. (D) Apo E secretion was evaluated by immunoblotting the culture medium from wild-type or CCT $\alpha$-deficient macrophages incubated for $18 \mathrm{~h}$ with and without LPS. Equal volumes of the culture medium were loaded onto the gel, and the immunoblot densities were quantified. The data are the mean \pm SE from two independent determinations using macrophages from a total of four mice of each genotype.

was measured by sampling the culture medium $18 \mathrm{~h}$ after addition of the ligand. Secretion of TNF $\alpha$, and interleukin-6 (IL-6) was reduced in the $\mathrm{CCT} \alpha$-deficient population, but the secretion of interleukin-1 $\beta$ (IL-1 $\beta$ ) was comparable to that in wild-type cells (Fig. 2 C). Both TNF $\alpha$ and IL-6 are delivered to the medium by vesicle-mediated secretion from the Golgi apparatus. IL-1 $\beta$ is transported by ATP-dependent secretion of specialized lysosomes that bypass the Golgi compartment (Andrei et al., 2004). The release of prostaglandin $\mathrm{E}_{2}\left(\mathrm{PGE}_{2}\right)$ was also normal in the $\mathrm{CCT} \alpha-$ null cells (Fig. 2 C). Altogether, these data indicated that LPS signaling was intact and that secretion of cytokines from the Golgi apparatus was impaired in the $\mathrm{CCT} \alpha$-deficient macrophages.

A time course revealed reduced release of both $\mathrm{TNF} \alpha$ and IL-6 from the knockout cells into the medium (Fig. 3, A and C). Reduced cytokine secretion was reflected in reduced total production of the cytokines (Fig. S1, available at http://www .jcb.org/cgi/content/full/jcb.200706152/DC1). Immunoblotting of cell lysates at 12 and $24 \mathrm{~h}$ after stimulation showed that TNF $\alpha$ accumulated in the $\mathrm{CCT} \alpha$-deficient macrophages as both the precursor and the mature form (Fig. $3 \mathrm{~B}$ ). In contrast, the membranebound precursor form of $\mathrm{TNF} \alpha$ ( $\mathrm{pro}-\mathrm{TNF} \alpha$ ) was quantitatively processed to the soluble mature form and completely released from the wild-type cells by $24 \mathrm{~h}$. TNF $\alpha$ processing is concurrent with its movement from the Golgi to the cell surface and mediated by a metalloprotease called TNF $\alpha$-converting enzyme (TACE; Gearing et al., 1994, 1995). A TACE inhibitor, $N$-(D,L-[2-(hydroxyaminocarbonyl)methyl]-4-methylpentanoyl)-L3-(2'naphthyl)-alanyl-L-alanine, 2-aminoethylamide (TAPI; Crowe et al., 1995), was added to wild-type macrophages after LPS addition to inhibit $\mathrm{TNF} \alpha$ processing and confirm the identification of the pro-TNF $\alpha$ on the blots (Fig. 3). TAPI abolished TNF $\alpha$ release to the medium, but TAPI did not inhibit IL-6 secretion from wild-type cells (Fig. S2). The data demonstrated that LPS signaling and cytokine synthesis were intact in the CCT $\alpha$ deficient macrophages. Because IL-6 secretion was not compromised, the inhibition of TACE activity by PtdCho deficiency was ruled out as a mechanism for the $\mathrm{TNF} \alpha$ secretion defect. Constitutive secretion of apolipoprotein E (ApoE) was not dependent on LPS stimulation and was not impaired in the CCT $\alpha$ null cells (Fig. 3 D). The synthesis of ApoE is repressed at the transcript level after LPS stimulation (Gafencu et al., 2007), and, thus, the amount released to the medium was reduced in both wild-type and knockout cells at later times after LPS stimulation (Figs. 3 D and S3 A). Imaging of cellular TNF $\alpha$ and ApoE 

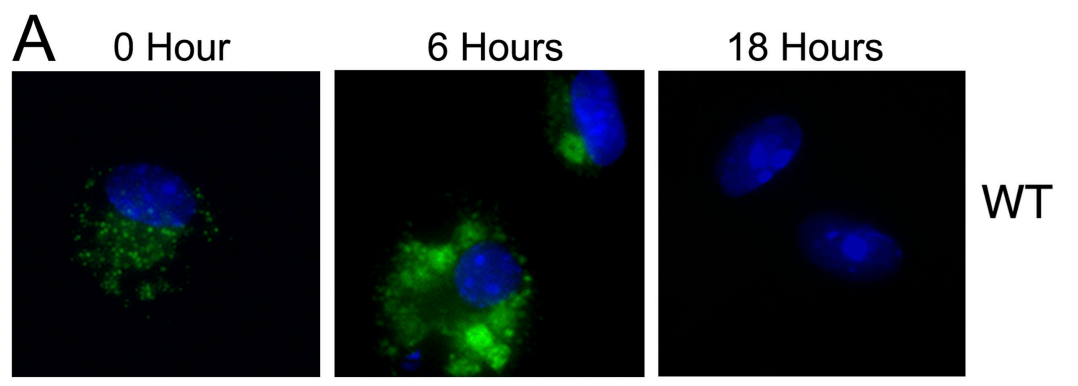

Figure 4. TNF $\alpha$ and IL- 6 accumulation in the CCT $\alpha$ deficient macrophages. (A) Wild-type (WT) or CCT $\alpha$ deficient $(\mathrm{KO})$ macrophages were treated with LPS, fixed, and stained with anti-TNF $\alpha$ antibody (green) at 0,6 , or $18 \mathrm{~h}$. (B) Wild-type or CCT $\alpha$-deficient macrophages were treated with LPS and stained with anti-IL-6 antibody (green) at 0,6 , or $18 \mathrm{~h}$. Cell nuclei in A and B were counterstained with DAPI (blue). At least 100 cells were visualized in each of two independent experiments. Bar, $10 \mu \mathrm{m}$.
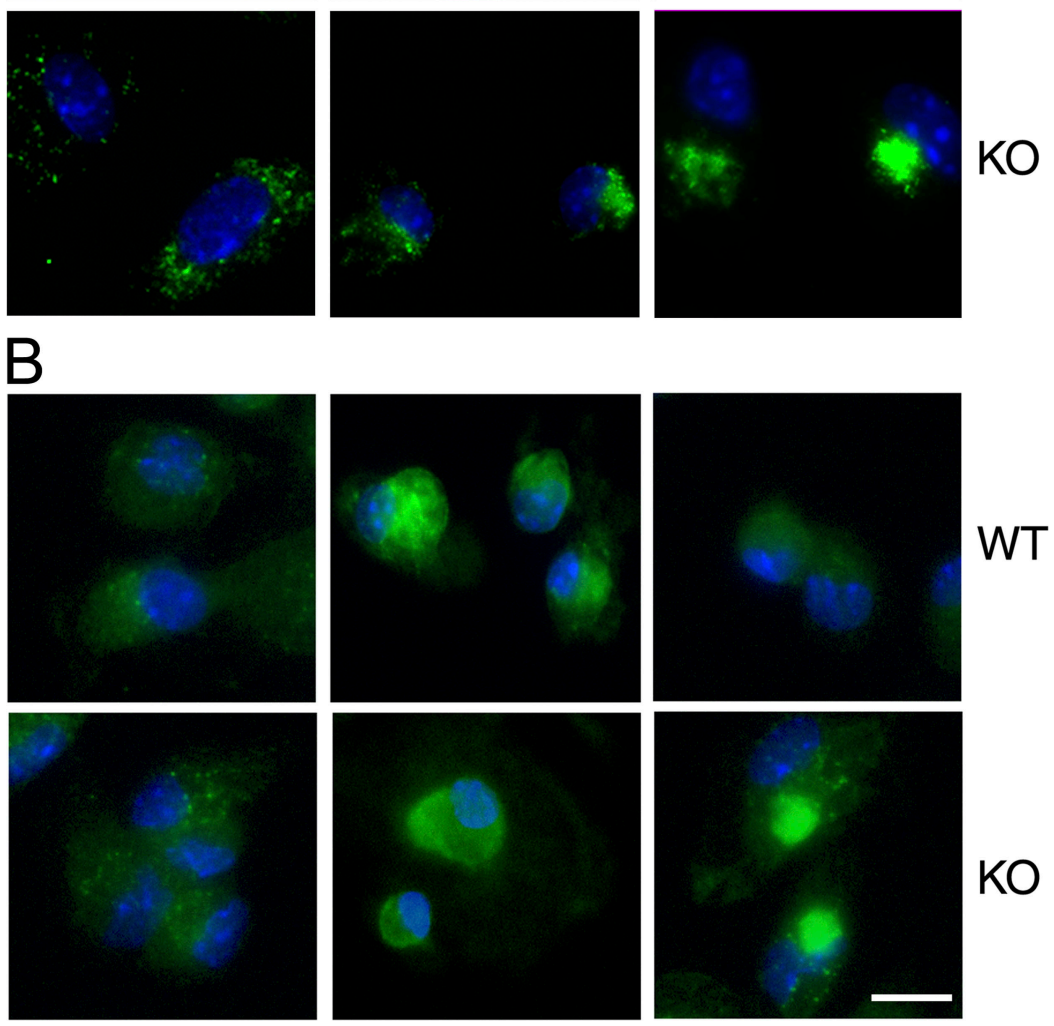

in the same cells indicated that these secretory products were located in different compartments (Fig. S3 B), which supports the view that ApoE exited from the Golgi compartment via different vesicles. New PtdCho biosynthesis was not required for secretion of ApoE but was necessary for the release of TNF $\alpha$ and IL- 6 after LPS stimulation.

The process of cytokine synthesis and secretion in the macrophages was investigated using immunocytochemistry. Wild-type and knockout cells were treated with LPS for 6 and $18 \mathrm{~h}$ before fixation and then stained with anti-TNF $\alpha$ or antiIL-6 antibodies (Fig. 4, A and B). The images confirmed that the $\mathrm{CCT} \alpha$-deficient cells were able to synthesize TNF $\alpha$ and IL-6. Intracellular TNF $\alpha$ and IL- 6 were detected at $6 \mathrm{~h}$, whereas wildtype cells were negative for these cytokines by $18 \mathrm{~h}$ after LPS stimulation. These results correlated with cellular cytokine synthesis and secretion to the medium. However, both cytokines were still retained within the CCT $\alpha$-deficient cells up to $48 \mathrm{~h}$ after LPS stimulation.

The results described thus far were obtained using thioglycolate-elicited macrophages that were isolated by peritoneal lavage and cultured in vitro. The physiological relevance of the phenotype was tested in vivo to ensure that the findings were not artifacts of manipulation of the cells or the in vitro system. The numbers of circulating monocytes, peritoneal macrophages, and bone marrow macrophages in the knockout animals were the same or slightly greater than those from the wild-type mice (Fig. S4, available at http://www.jcb.org/cgi/content/full/jcb .200706152/DC1). We subjected both wild-type and knockout mice to infection with an intranasal dose $\left(10^{7}\right.$ colony-forming units) of luminescent Streptococcus pneumoniae strain T4X and followed the course of the infection in five to six individual littermate mice of each genotype (Fig. 5 A). Wild-type mice developed mild pneumonia and between 10 and 50\% succumbed in three independent experiments. In contrast, mice with $\mathrm{CCT} \alpha$-deficient macrophages developed more serious diffuse pneumonia, with higher bacterial counts, and the disease quickly progressed to sepsis (Fig. 5 A), with a mean $70 \%$ mortality rate (Fig. 5 B). In lungs of knockout animals, there were extensive areas of interstitial pneumonia with consolidation, necrosis, and marked fibrinopurulent pleuritis (Fig. $5 \mathrm{C}$, top). The inflammatory infiltrate in the pneumonic areas was composed of viable and degenerate neutrophils, macrophages, and perivascular cuffs of lymphocytes and plasma cells. In lungs of wild-type mice, there were patchy mild interstitial inflammatory infiltrates composed primarily of 

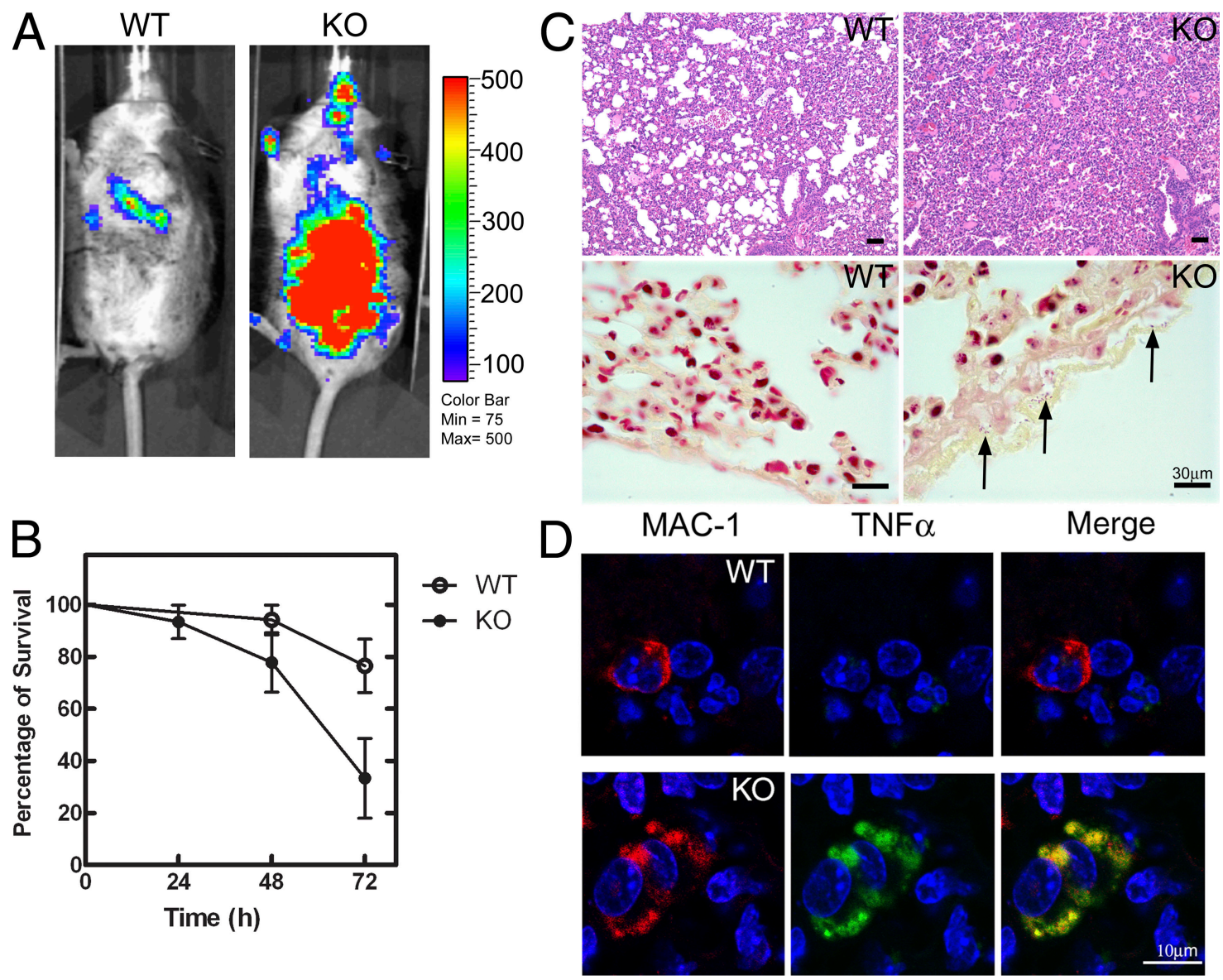

$\mathrm{TNF} \alpha$
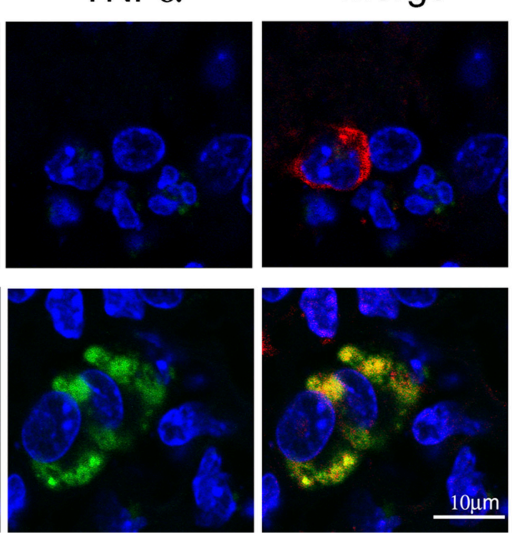

Figure 5. Aberrant cytokine release from CCT $\alpha$-deficient macrophages after bacterial infection. (A) Distribution of S. pneumoniae LUX at $3 \mathrm{~d}$ after intranasal challenge. Bacterial numbers are proportional to the color bar on the right. Note the small focus of bacteria in lungs of the wild-type (WT) mouse versus systemic bacteremia in the knockout (KO) mouse. Images are representative of the mice from three independent experiments. (B) Survival of mice with wild-type $(O ; n=16)$ or CCT $\alpha$-deficient $\left(0_{n} n=16\right)$ macrophages after bacterial challenge. The results were compiled from three independent experiments. Error bars indicate mean \pm SE. (C) Lung pathology at $3 \mathrm{~d}$ after infection. Hematoxylin and eosin staining (top) illustrates more severe pneumonia and Gram's staining (bottom) illustrates increased bacterial proliferation (arrows) with CCT $\alpha$-null macrophages. Bars, $30 \mu \mathrm{m}$. (D) 10- $\mu \mathrm{m}$-thick frozen sections obtained from mouse lung tissue. Infiltrating macrophages $48 \mathrm{~h}$ after infection were identified by positive MAC-1 staining (red) and TNF $\alpha$ staining (green), and cells were counterstained with DAPI (blue). MAC-1-positive signals, 11-15 per 40x field, from alveolar and interstitial macrophages were examined using three slides from each infected lung in three individual mice of each genotype. In lungs from animals with wild-type macrophages, a mean of $18 \%$ MAC-1-positive cells were TNF $\alpha$ positive, and with CCT $\alpha$-null macrophages, a mean of $82 \%$ MAC-1-positive cells were TNF $\alpha$ positive. Cell nuclei are indicated as DAPI-positive (blue).

neutrophils with fewer macrophages and perivascular and peribronchiolar infiltrates of lymphocytes and plasma cells. A Gram's stain to detect bacteria in the lung tissue revealed abundant cocci in the knockout animals (Fig. $5 \mathrm{C}$, bottom), particularly embedded in the layers of fibrin along the pleural surface (arrows), whereas Gram-positive cocci were rarely observed in the wildtype lungs. The numbers of macrophages in the knockout model were equivalent to the numbers in wild-type animals (Fig. S4, $\mathrm{A}-\mathrm{C}$ ), and the knockout macrophages at the site of infection accumulated and retained $\mathrm{TNF} \alpha$, in contrast to the wild-type macrophages (Fig. 5 D). The macrophages that infiltrated the lungs $48 \mathrm{~h}$ after infection were identified in cryosections with an antiMAC- 1 antibody and counterstained with an anti-TNF $\alpha$ antibody. The wild-type macrophages were devoid of the cytokine by this time, but the majority of knockout cells still retained a strong signal, which indicates that the cytokine had not yet been released into the extracellular space (Fig. 5 D). These data supported the hypothesis that $\mathrm{CCT} \alpha$ deficiency caused the macrophages to accumulate $\mathrm{TNF} \alpha$ and impaired cytokine secretion in vivo.

The reorganization of the Golgi apparatus after LPS stimulation was compared between wild-type and $\mathrm{CCT} \alpha$-deficient macrophages using an antibody that recognizes the ER-Golgi intermediate compartment 53-kD protein (ERGIC-53), a protein specifically localized in the ER and cis-Golgi compartment (Litvak et al., 2005). The images indicated only limited rearrangement of the marker protein after LPS stimulation and a similar distribution in both wild-type and knockout cells (Fig. 6). Next, the trans-Golgi compartment was imaged with an antibody that recognizes the K58 marker protein (Bloom and Brashear, 1989). K58 was located proximal to the cell nucleus and surrounded $30-50 \%$ of the nucleus before LPS stimulation. In wild-type cells, the K58 protein coalesced into a focused structure at a distinct perinuclear site by $6 \mathrm{~h}$ and then returned to the more diffuse distribution characteristic of unstimulated cells at $18 \mathrm{~h}$ after LPS activation (Fig. 6). In the CCT $\alpha$-deficient 

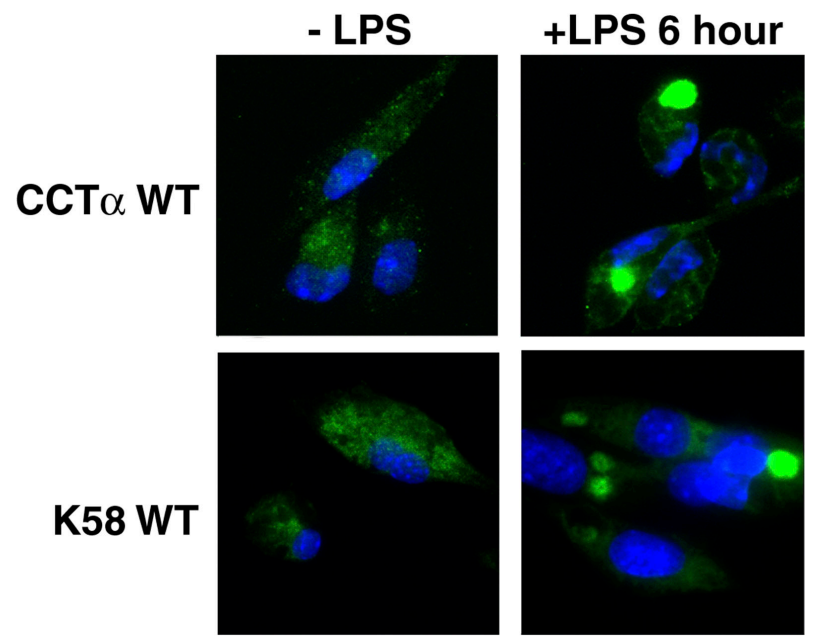

K58 WT
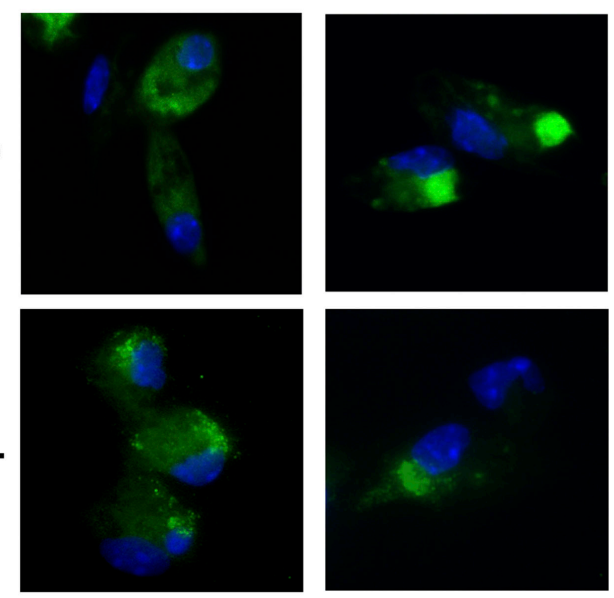

\section{ERGIC-53 WT}
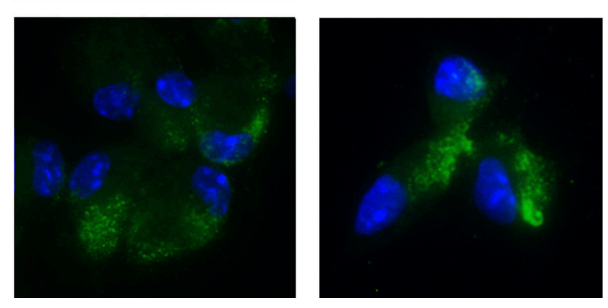

\section{ERGIC-53 KO}

cells, the K58 marker behaved similarly to wild-type cells, except that the K58 protein was still intensely focused in a single region adjacent to the nucleus by $18 \mathrm{~h}$ after LPS stimulation. Interestingly, the CCT $\alpha$ protein in the wild-type, stimulated primary macrophages was associated with the Golgi compartment (Fig. 6). The CCT $\alpha$ signal converged by $6 \mathrm{~h}$ after LPS treatment and then redistributed to the more diffuse distribution surrounding up to $50 \%$ of the nucleus, similar to the K58 marker. The CCT $\alpha$ protein was not visualized in $\sim 80 \%$ of the knockout macrophage population, and cells that expressed CCT $\alpha$ did not retain TNF $\alpha 18 \mathrm{~h}$ after LPS (Fig. S4 E). The CCT $\beta$ proteins did not redistribute after LPS treatment (Fig. S4 D). These data indicated that the $\mathrm{CCT} \alpha$ protein in primary macrophages localized to the trans-Golgi region and that this compartment was the site of the Golgi dysfunction in the cytokine secretion pathway of CCT $\alpha$-deficient cells.

The biochemical defect underlying the phenotype in the knockout cells could be caused by an imbalance in several different lipids. PtdCho is metabolized to $\mathrm{PtdOH}$ in the Golgi or-
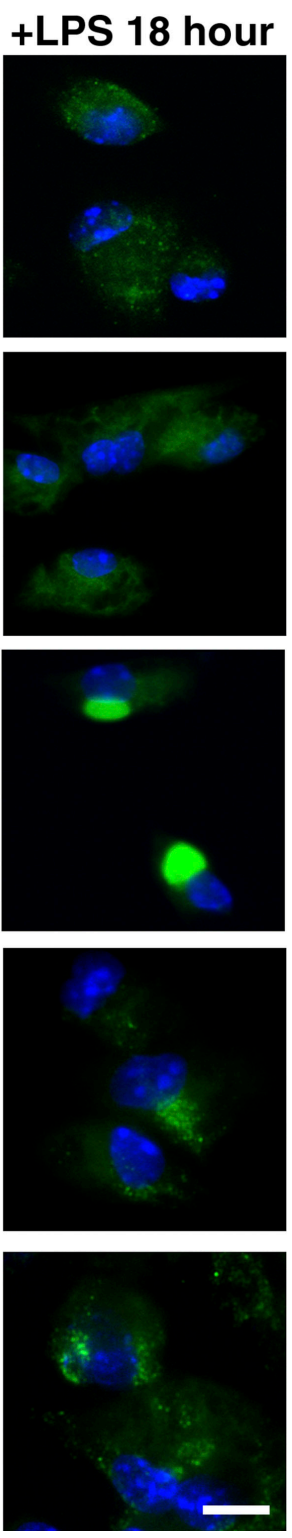

Figure 6. Distributions of Golgi markers in LPS-treated macrophages. Wild-type (WT) and knockout (KO) peritoneal macrophages were treated with LPS at $10 \mathrm{ng} / \mathrm{ml}$ for 0,6 , and $18 \mathrm{~h}$. After immediate fixation in $4 \%$ paraformaldehyde, cells were permeabilized and stained with antibodies against $\mathrm{CCT}_{\alpha}$ (green), the trans-Golgi marker K58 (green), or the cisGolgi marker ERGIC-53 (green). Cell nuclei were counterstained with DAPI (blue). Each micrograph shown in the figure is representative of macrophages from at least four independent mice. Bar, $15 \mu \mathrm{m}$. ganelle by a PLD, which is activated by secretory stimuli. PtdOH is in turn rapidly converted to DAG by a PtdOH P'tse. PtdCho is also the metabolic precursor to sphingomyelin (SM), a lipid that is synthesized in the Golgi compartment and then transported to the cell surface. Measurement of the amount before and $18 \mathrm{~h}$ after LPS stimulation revealed that the PtdCho was significantly reduced in the CCT $\alpha$-deficient cells after LPS, in contrast to the wild-type cells, where the PtdCho level was maintained after stimulation (Fig. 7 A). In contrast, the amount of total protein per cell was the same in wild-type and knockout cells both before and after LPS (Fig. S4 F). Phosphatidylethanolamine (PtdEtn), the second most abundant phospholipid in intracellular membranes, did not change significantly in the knockout cells after LPS stimulation (Fig. S5 A, available at http://www.jcb .org/cgi/content/full/jcb.200706152/DC1). The DAG levels in $\mathrm{CCT} \alpha$-deficient cells increased significantly but remained the same in wild-type after LPS stimulation (Fig. 7 B). SM was reduced to the same apparent level with no statistical difference between the wild-type and knockout cells (Fig. 7 C). These data 

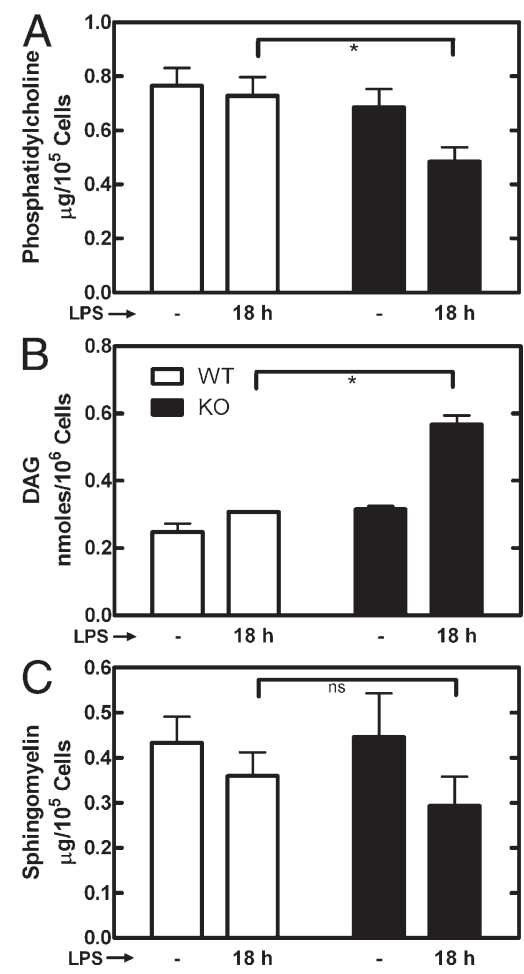

Figure 7. Amounts of PtdCho, DAG, and SM after LPS stimulation. Wildtype (WT; white) and CCT $\alpha$-deficient (KO; black) macrophages were incubated with $10 \mathrm{ng} / \mathrm{ml}$ LPS or without LPS for $18 \mathrm{~h}$, and total lipids were extracted. The identification of PtdCho (A) and SM (C) was determined by TLC and comigration with authentic standards, and the amount of each lipid was quantified by flame ionization using the latroscan calibrated with known amounts of each standard. The amount of DAG (B) was determined by the DAG kinase assay. Values were normalized to cell numbers. Data are the mean of determinations from at least two individual mice of each genotype. Error bars indicate mean $\pm \mathrm{SE}$. ns, not significant; ${ }^{*}, \mathrm{P}<0.05$.

indicated a biochemical imbalance in the PtdCho and DAG but normal SM metabolism in the CCT $\alpha$-deficient cells. To confirm that SM synthesis was unaffected in the knockout cells, macrophages were radiolabeled with $\left[{ }^{3} \mathrm{H}\right]$ choline for $6 \mathrm{~h}$ with or without LPS. The data showed that SM synthesis did not change after LPS treatment of wild-type cells and that SM synthesis in the knockouts was the same as the wild type (Fig. S5 B). Meanwhile, data from the same experiments demonstrated that the rate of PtdCho synthesis was reduced in the CCT $\alpha$-null macrophages both in the unstimulated cells and after LPS addition. Thus, the amount of PtdCho in the CCT $\alpha$-null cells was sufficient for SM production despite the reduced rate of PtdCho synthesis.

Both CDP-Cho and DAG are substrates for the CPT that makes PtdCho. Limitation of the CDP-Cho supply by genetic inactivation of the CCT $\alpha$ accounted for the reduced PtdCho and for the metabolic accumulation of DAG after LPS. Affymetrix microarray data, available at the National Center for Biotechnology Information website (Gene Expression Omnibus; http://www .ncbi.nlm.nih.gov/; Shell et al., 2005), revealed that expression of a select group of lipid metabolic genes increased $18 \mathrm{~h}$ after LPS stimulation of wild-type macrophages, including those encoding the PLD1, the CCT $\alpha$, and the choline/ethanolamine phosphotransferase (C/EPT; Table S1, available at http://www

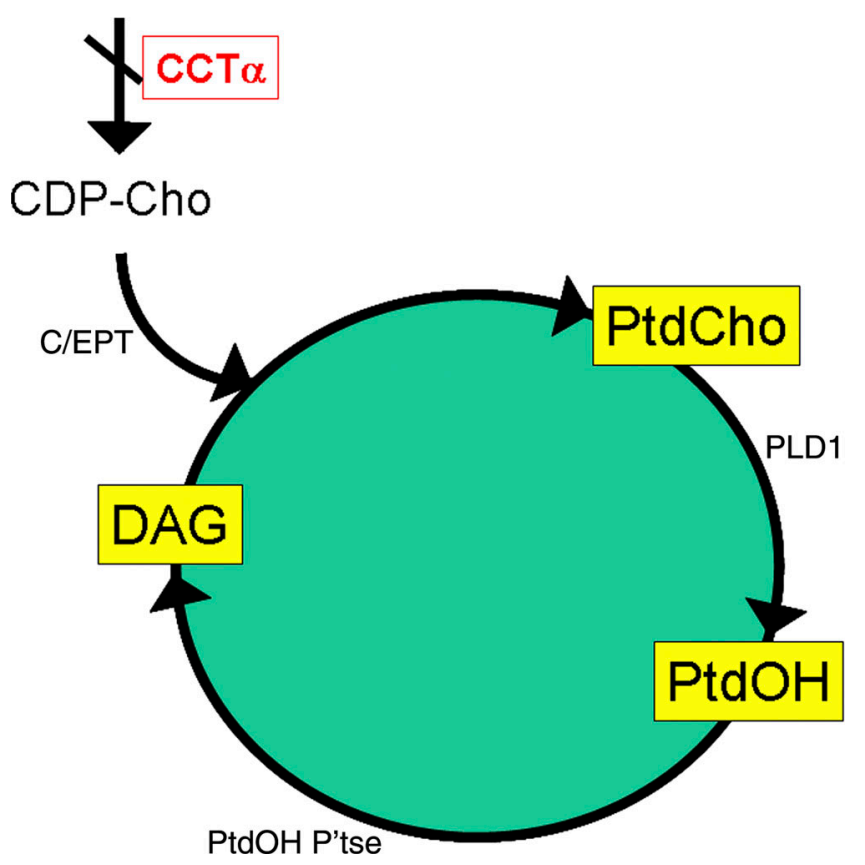

Figure 8. Cycle of PtdCho degradation and resynthesis associated with secretion from the Golgi apparatus. PtdCho is degraded by a PLDI to $\mathrm{PtdOH}$, which in turn is converted to DAG by a PtdOH P'tse during secretion from the trans-Golgi compartment. The C/EPT utilizes DAG and CDP-Cho to form PtdCho and replenish the Golgi-associated PtdCho pool.

.jcb.org/cgi/content/full/jcb.200706152/DC1; Shell et al., 2005). We confirmed the data using real-time qRT-PCR on total RNA extracted from wild-type macrophages before and $18 \mathrm{~h}$ after LPS stimulation, and found a statistically significant increase in the expression of these genes (Fig. S5 E). This information indicated the isoforms of each enzyme that worked together with the CCT $\alpha$ to control phospholipid metabolism during LPSstimulated cytokine secretion. Taken together, the data support the existence of a cycle of PtdCho degradation and resynthesis that accompanies cytokine secretory vesicle formation and budding from the Golgi complex (Fig. 8).

A pharmacological approach was used to test several aspects of this hypothesis. Et-18-- $\mathrm{OCH}_{3}$ (edelfosine), an inhibitor of CCT (Boggs et al., 1995a), dramatically reduced TNF $\alpha$ secretion in cells of both genotypes (Fig. 9 A). Incubation with lysophosphatidylcholine (lysoPC), which is rapidly converted to PtdCho (Baburina and Jackowski, 1999), bypassed the CCT $\alpha$ genetic defect (Esko et al., 1982; Boggs et al., 1995b; Baburina and Jackowski, 1998) and partially restored $\mathrm{TNF} \alpha$ secretion from CCT $\alpha$-deficient cells (Fig. 9 A). The LysoPC pathway would replenish PtdCho but would not remove DAG. In fact, measurement of the DAG level in lysoPC-treated knockout cells revealed that the DAG level increased (Fig. S5 F). This result was probably caused by inhibition of CCT $\beta 3$ by lysoPC, which has been shown to interfere with the membrane association and activation of the enzyme (Boggs et al., 1995a; Attard et al., 2000). Treatment of cells with either 1-butanol to inhibit phospholipase D activity, or propranolol to inhibit PtdOH P'tse activity, also inhibited TNF $\alpha$ secretion (Fig. 9 B). These results support the involvement of the phospholipase D pathway in secretion. However, fumoni$\sin$ B1, an inhibitor of ceramide and SM synthesis, had no effect. 

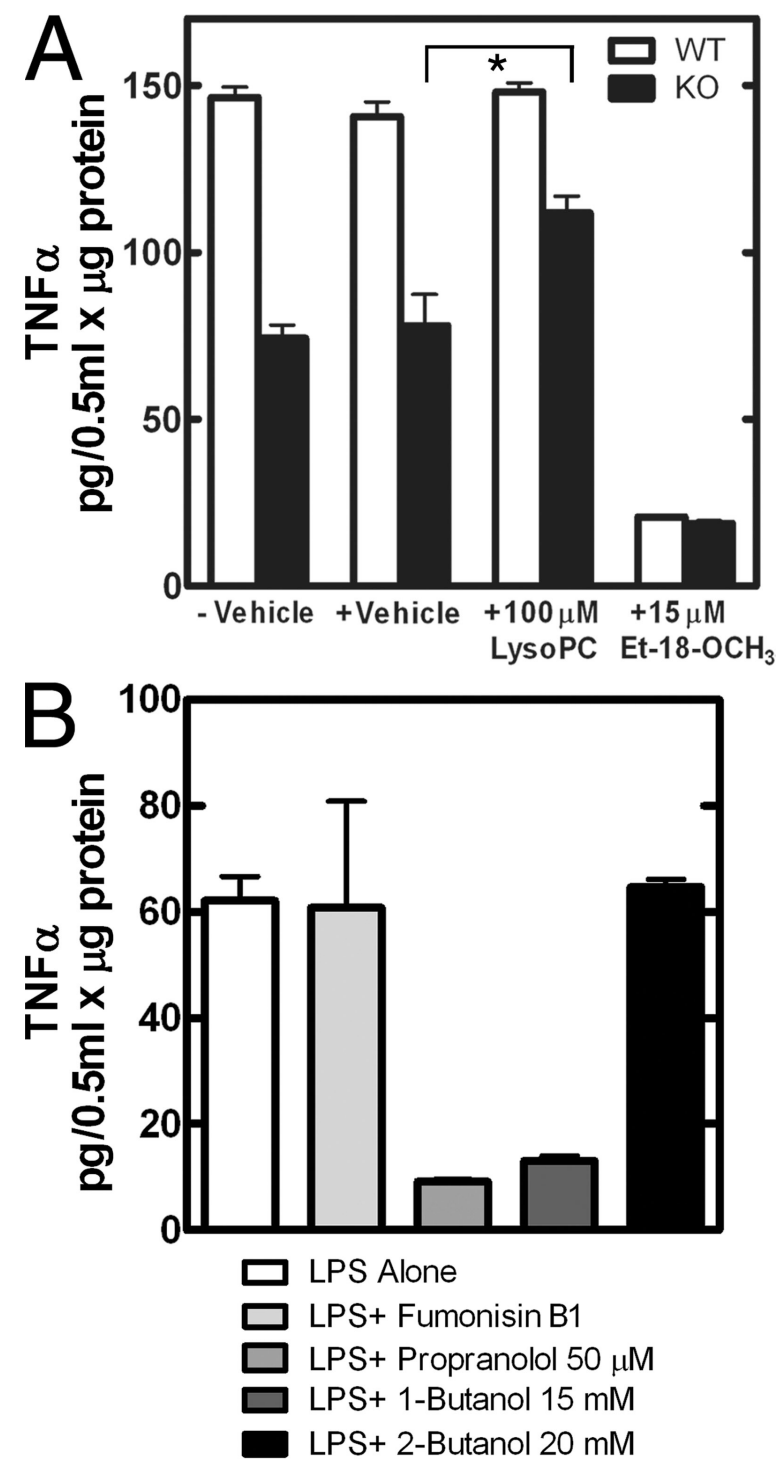

Figure 9. Response of TNF $\alpha$ secretion to different treatments. (A) Wildtype (WT; white bars) or CCT $\alpha$-deficient (KO; black bars) macrophages were treated with $10 \mathrm{ng} / \mathrm{ml}$ LPS for $18 \mathrm{~h}$. At the same time, $100 \mu \mathrm{M}$ LysoPC, $15 \mu \mathrm{M}$ edelfosine, or solvent vehicle $(0.1 \%$ ethanol) were added to the medium as indicated. The amount of $\mathrm{TNF} \alpha$ secreted into the culture medium was determined using a Quantikine kit, and results are the mean values normalized to cellular protein $(n=8)$ obtained from four mice of each genotype. (B) Wild-type cells were treated with $10 \mathrm{ng} / \mathrm{ml}$ LPS alone, with LPS plus $10 \mu \mathrm{M}$ fumonisin $\mathrm{B} 1$ to inhibit ceramide synthesis, with LPS plus $50 \mu \mathrm{M}$ propranolol to inhibit the PtdOH P'tse, with LPS plus $15 \mathrm{mM}$ 1-butanol to inhibit the phospholipase D, and with LPS plus $20 \mathrm{mM}$ 2-butanol as an alcohol control for $8 \mathrm{~h}$. Data are the mean of determinations from four individual mice of each genotype. Error bars indicate mean $\pm \mathrm{SE} .{ }^{*}, \mathrm{P}<0.05$

These results confirmed that the cellular defect was caused by reduced PtdCho synthesis and did not extend to an imbalance in SM synthesis (Fig. 9 B). SM synthesis and TNF $\alpha$ and IL-6 release to the medium were measured in the same experiment in the presence and absence of fumonesin B1 in wild-type cells. Although SM synthesis was severely reduced, the amount of either cytokine in the medium was the same with or without inhibitor treatment (Fig. S5, C and D). Nor did 2-butanol have an effect, which was a treatment control for the specificity of the phospholipase D
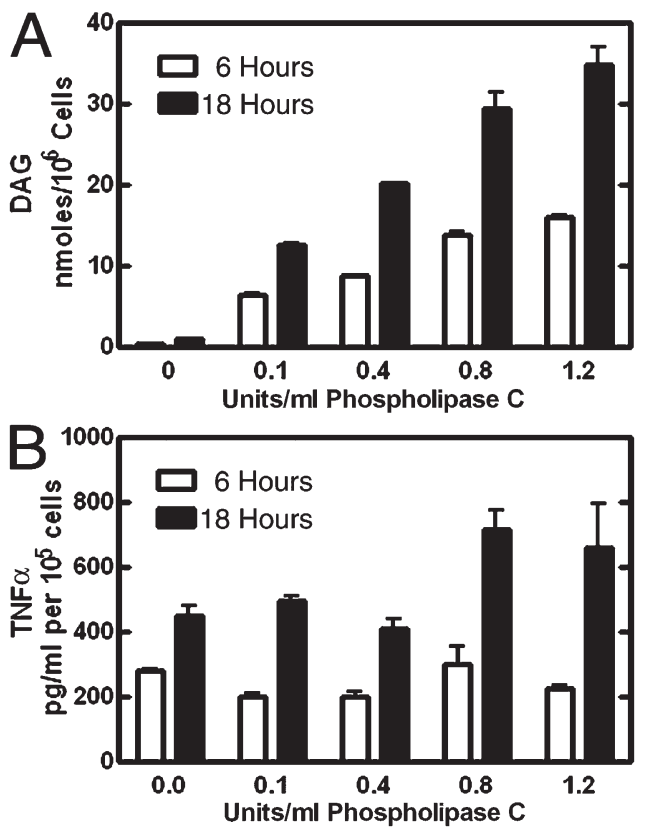

Figure 10. Cell-associated DAG and TNF $\alpha$ release to the medium after LPS and exogenous phospholipase $C$. Wild-type macrophages were treated with LPS for $3 \mathrm{~h}$, then $B$. cereus phospholipase $C$ was added at the indicated concentrations for the remainder of the 6-and 18-h incubations. (A) Cells were harvested for lipid extraction, and the amount of DAG was determined by the DAG kinase assay as described in Materials and methods. The values were normalized to cell numbers. (B) TNF $\alpha$ was quantified in the medium using the ELISA method. The values were normalized to cell number. The data are the mean of values obtained using cells from three mice. Error bars indicate mean \pm SE.

inhibition by 1-butanol (Fig. 9 B). Taken together, these data support the idea that de novo PtdCho synthesis was required to maintain cytokine secretion from the Golgi apparatus in LPSstimulated macrophages.

DAG levels were increased to test whether impaired secretion would be the result. At $3 \mathrm{~h}$ after LPS stimulation, wild-type cells were incubated with increasing concentrations of a phospholipase $\mathrm{C}$ isolated from Bacillus cereus. The phospholipase $\mathrm{C}$ in the medium converted surface membrane PtdCho to DAG. We reasoned that at least a portion of the DAG would relocate intracellularly to the Golgi apparatus, similar to the supplemental lysoPC in the medium that resulted in rescue of the phenotype (Fig. 9). At 6 and $18 \mathrm{~h}$ after addition of the enzyme, the amount of TNF $\alpha$ in the medium and the amount of DAG in the cells was quantified (Fig. 10). Despite substantial increases in DAG that correlated with the amount of phospholipase $\mathrm{C}$ added (Fig. 10 A), TNF $\alpha$ secretion was not impaired (Fig. $10 \mathrm{~B}$ ). These data argued that increased DAG was not the critical biochemical factor leading to the knockout phenotype. Rather, depletion of the PtdCho supply impeded vesicular transport, resulting in accumulation of cytokines in the Golgi apparatus.

\section{Discussion}

Our interpretation of the inhibition of induced cytokine secretion from the knockout cells is that the PtdCho requirement for cytokine trafficking arises from the inability to supply PtdCho 
to the Golgi apparatus. The PtdCho degradation mediated by phospholipase D that accompanies cytokine secretion in LPS-stimulated cells depletes PtdCho in the absence of CCT $\alpha$ dependent de novo synthesis, resulting in a lipid imbalance exemplified by an increase in DAG. The activities and Golgi localizations of both CCT $\alpha$ and the C/EPT in wild-type cells enable rapid resupply of PtdCho. The residual CCT activity in the knockout cells, caused by CCT $\beta 3$ expression, is not sufficient or not located in the appropriate cellular compartment (Fig. S4 D) to provide the PtdCho necessary to support cytokine secretion. Two datasets support this interpretation: the lower rate of PtdCho synthesis in the knockout cells compared with the wild type (Figs. $1 \mathrm{~A}$ and S5 A) and the lower amount of PtdCho per cell in the CCT $\alpha$ knockouts after LPS stimulation (Fig. 7 A). In contrast, ApoE secretion is not dependent on de novo PtdCho synthesis (Figs. $3 \mathrm{D}$ and S3). The data indicate that ApoE protein exits the Golgi compartment by a pathway distinct from the TNF $\alpha$ and IL- 6 cytokines. ApoE is concentrated in a subclass of Golgi-derived vesicles distinct from those vesicles that contain secretory albumin (Gusarova et al., 2007). ApoE secretion is linked to cellular sphingolipid synthesis (Lucic et al., 2007), and neither process is impaired in the $\mathrm{CCT} \alpha$ knockout macrophages (Figs. $7 \mathrm{C}$ and S5 B).

$\mathrm{CCT} \alpha$ participates in a cycle of PtdCho degradation and resynthesis illustrated in Fig. 8. The ER is a major cellular site for membrane biogenesis (Fagone et al., 2007; Sriburi et al., 2007), and new phospholipid is distributed throughout the cell via membrane lateral diffusion, vesicular transport, or protein carriers to other membrane-delimited organelles (Trotter and Voelker, 1994). The replenishment of PtdCho and the removal of DAG in the Golgi can occur via these transport processes. However, our experiments suggest that CCT $\alpha$ expression (Fig. S5 E and Table S1) and association with the trans-Golgi compartment (Fig. 6) are required to provide new $\mathrm{CDP}-\mathrm{Cho}$ that is used by the Golgilocalized C/EPT (Fig. S5 E and Table S1) to resupply PtdCho. The heightened activity of phospholipase D (Bi et al., 1997; Corda et al., 2002; Freyberg et al., 2003; Jenkins and Frohman, 2005) during LPS-stimulated cytokine secretion degrades the Golgi-associated PtdCho and yields DAG. A threshold level of DAG is required for secretion in yeast (Kearns et al., 1997) and HeLa cells (Litvak et al., 2005; Lev, 2006). The DAG recruits specific proteins to the Golgi apparatus that function in vesicular transport (Patton-Vogt et al., 1997; Roth, 1999; Baron and Malhotra, 2002; Corda et al., 2002) and induces curvature in the phospholipid bilayer that is postulated to promote membrane fusion and fission events (Shemesh et al., 2003). However, our results indicate that aberrantly high DAG does not impede vesicular transport from the Golgi complex (Fig. 10, A and B; and Fig. S5 F).

The association of CCT $\alpha$ with the trans-Golgi compartment during TNF $\alpha$ secretion (Fig. 6) is consistent with its ability to translocate to membranes enriched in DAG and become activated. CCT $\alpha$ reversibly binds to biological membranes via its amphipathic $\alpha$-helical domain, and DAG is among the most potent membrane components that promote $\mathrm{CCT} \alpha$ binding in vitro and in vivo (Kent, 1997; Cornell and Northwood, 2000; Jackowski and Fagone, 2005; Cornell and Taneva, 2006). CCT $\alpha$ membrane association is not specific for DAG but rather correlates with the membrane curvature elastic stress that is induced by accumulation of conically shaped membrane lipids (Attard et al., 2000). The binding of CCT $\alpha$ to membranes increases CDP-Cho production at the site of DAG formation to promote PtdCho synthesis by the Golgi-resident CPT or C/EPT enzymes (Henneberry et al., 2001). The association of the C/EPT isoform with the secretory compartment is suggested by its increased expression after LPS stimulation (Fig. S5 E and Table S1). Overexpression studies placed the CPT isoform at the Golgi apparatus and the C/EPT isoform with the ER (Henneberry et al., 2002). However, a later proteomics analysis of the endogenous components of the secretory pathway identifed C/EPT rather than CPT in the Golgi cisternae (Gilchrist et al., 2006). In addition, increased expression of CPT is associated with ER biogenesis in B cells (Fagone et al., 2007) and fibroblasts (Sriburi et al., 2004). Thus, our data (Fig. S5 E) suggest that the C/EPT is the likely participant in PtdCho synthesis associated with secretion from the Golgi apparatus.

Our findings in macrophages extend the relationship between PtdCho synthesis and vesicular trafficking uncovered in lower organisms. Recent studies in Drosophila melanogaster eye development indicate a role for CCT in regulation of the endocytic pathway that results in an altered subcellular localization of the EGF and Notch receptors (Weber et al., 2003). Similarly, the defects in ovarian development in D. melanogaster Cctl mutants are explained by defects in the secretion of signaling molecules through the Golgi apparatus (Gupta and Schüpbach, 2003). The relationship between Golgi function and PtdCho synthesis is most clearly revealed in the yeast system, where the arrest of Golgi-mediated secretion by mutations in sec14, a PtdCho/ phosphatidylinositol transfer protein, is overcome by mutations in the CDP-Cho pathway (Cleves et al., 1991; Huijbregts et al., 2000). Yeast synthesize the majority of their PtdCho through an alternate pathway; thus, inactivation of the CDP-Cho pathway is not lethal in that system. The importance of DAG production to mammalian Golgi function is also highlighted by the recent work with the Nir2 protein. Depletion of the Nir2 protein limits the production of DAG in the Golgi, inhibits protein transport from the trans-Golgi to the plasma membrane, and affects the structural integrity of the Golgi apparatus (Litvak et al., 2005). There is a distinct difference in CCT $\alpha$ localization, and perhaps its metabolic role, in transformed cultured cells compared with primary cells. Although CCT $\alpha$ is located in association with the Golgi complex and outside the nucleus in primary macrophages (Fig. 6), it is found predominantly within the nucleus of transformed macrophages and HeLa cells (Lykidis et al., 1999). In all of the primary cells examined thus far, including macrophages (this paper), lung secretory type II cells (Ridsdale and Post, 2004), and B lymphocytes (Fagone et al., 2007), the CCT $\alpha$ is located outside the nucleus and often in association with organellar membranes.

\section{Materials and methods}

\section{CCT $\alpha$-deficient macrophages}

Homozygous Pcytlaflox mice (Zhang et al., 2000) were obtained from I. Tabas (Columbia University, New York, NY) and bred with LysMCre mice (obtained from I. Förster, Technical University of Munich, Munich, Germany; courtesy of P. Murray, St. Jude Children's Research Hospital, Memphis, TN) as described previously (Clausen et al., 1999; Zhang et al., 2000) to obtain 
knockout and littermate wild-type macrophages. The two flox sites flanked a $12.5-\mathrm{kb}$ fragment of the gene containing exons 5-9 (renumbered; Karim et al., 2003), the intervening introns, and parts of introns 4 and 9. Deletion of the region between the flox sites resulted in loss of the catalytic domain of the CCT $\alpha$ protein. The resulting transcript encoded a truncated protein that lacked the catalytic domain and the regulatory domains located at the carboxy terminus. The Neo cassette and a third flox site that were originally inserted into the gene and used for embryonic stem cell selection of recombinants was removed by mating with an Ella Cre mouse (The Jackson Laboratory) to avoid hypomorphic effects on CCT $\alpha$ expression in the undeleted macrophages from littermates (Zhang et al., 2000). Genotyping of tails and macrophages was performed as described previously (Zhang et al., 2000). Macrophages were elicited by injection of $3 \mathrm{ml}$ thioglycolate (Becton Dickinson) followed by peritoneal lavage with PBS containing $5 \mathrm{U} / \mathrm{ml}$ heparin. After hypertonic lysis of the erythrocytes using $10 \mathrm{mM} \mathrm{KHCO}$, $150 \mathrm{mM} \mathrm{NH}_{4} \mathrm{Cl}$, and $0.1 \mathrm{mM} \mathrm{Na} 2$ EDTA, pH 7.65, macrophages were cultured in $\mathrm{L}$ cell-conditioned medium (LCM) as described previously (Tang et al., 1999). LPS from E. coli (Sigma-Aldrich) was dissolved in PBS, and optimized concentrations were 10 or $100 \mathrm{ng} / \mathrm{ml}$ and lot number-dependent.

\section{CCT activity and expression}

CCT activities in macrophage cell lysates were determined essentially as described previously (Luche et al., 1993). Protein concentration was determined according to the Bradford method using $\gamma$-globulin as a standard (Bradford, 1976). Total RNA was isolated from cells using TRIzol reagent (Invitrogen) as described previously (Wang et al., 2005). Realtime PCR was used to determine the relative expression levels of the $\mathrm{CCT} \alpha, C C T \beta 2, C С T \beta 3$, and phosphatidylethanolamine methyltransferase (PEMT) isoform transcripts encoded by the Pcytla, Pcytlb, and Pemt genes as described previously (Jackowski et al., 2004). Immunoblotting with CCT isoform-specific antibodies has been described previously (Lykidis et al., 2001).

\section{Lipid analysis}

$2.5 \times 10^{5}$ macrophages were plated in $60-\mathrm{mm}$ dishes and incubated overnight in LCM. For radiolabeling experiments, adherent cells were incubated in fresh $\mathrm{LCM}$ containing either $1 \mu \mathrm{Ci} / \mathrm{ml}\left[\right.$ methyl- $\left.{ }^{3} \mathrm{H}\right]$ choline chloride or $10 \mu \mathrm{Ci} / \mathrm{ml}\left[{ }^{3} \mathrm{H}\right]$ palmitic acid (American Radiolabeled Chemicals, Inc.) \pm $10 \mathrm{ng} / \mathrm{ml}$ LPS for the time indicated in the figure legends. Lipids were extracted as described previously (Bligh and Dyer, 1959) and fractionated on preadsorbent $\mathrm{H}$ silica thin-layer plates (Analtech) developed with chloroform/methanol/acetic acid (98:2:1) or chloroform/methanol/ ammonium hydroxide (60:35:8). Areas corresponding to PtdCho, PtdEtn, and SM standards were counted. For measurements of lipid quantity, extracted lipid mixtures were fractionated on silica gel rods using the same solvent systems, and the amount of each identified lipid was quantified by flame ionization using an latroscan (latron Instruments). DAG was quantified in lipids extracted from cells as described previously (Preiss et al., 1987) and normalized to cell number. Protein was quantified by the Bradford method (Bradford, 1976).

\section{Phagocytosis assays}

Macrophages were plated at a density of $10^{5}$ per well in 96-well black plates (Corning) and cultured overnight in LCM. A bacterial suspension containing $\sim 1 \times 10^{8}$ fluorescent bacteria from the Vybrant phagocytosis assay kit (Invitrogen) was added and incubated for 2 or $4 \mathrm{~h}$ at $37^{\circ} \mathrm{C}$. Quantification was performed according to the manufacturer's instructions on a Fusion Universal Microplate Analyzer plate reader (PerkinElmer). $10 \mu \mathrm{g} / \mathrm{ml}$ DAPI (Invitrogen) was added to determine cell numbers.

\section{Chemotaxis assays}

Cell migration assays were performed in 96-well MultiScreen-MIC plates (Millipore) with 5-mm-pore-sized polycarbonate membrane. $10 \mathrm{nM}$ fMLP (EMD) was or was not added to the lower wells. Cells that migrated after $4 \mathrm{~h}$ were stained with Calcein AM quantified using a Fusion Universal Microplate Analyzer plate reader.

\section{Cytokine and prostaglandin assays}

Macrophages were cultured with LCM containing 10-100 ng/ml LPS, and, as indicated, $200 \mu$ l aliquots of culture medium were removed and assayed for TNF $\alpha$, IL-6, IL-1 $\beta$, or PGE 2 content by ELISA (Quantikine R\&D Systems; Cayman Chemical) according to the manufacturer's instructions. The antibody used in the TNF $\alpha$ ELISA recognized both the precursor pro-TNF $\alpha$ and the mature TNF $\alpha$ isoforms. Where indicated, cells were harvested and lysates were prepared as described previously (Mbebi et al., 2005). In brief, cultured cells were washed three times with ice-cold PBS and lysed in $20 \mathrm{mM}$ Tris- $\mathrm{HCl}$, pH 7.5, containing $150 \mathrm{mM} \mathrm{NaCl}, 2 \mathrm{mM}$ EDTA, $1 \%$ Triton X-100, $10 \mathrm{Mg} / \mathrm{ml}$ leupeptin, $10 \mathrm{Mg} / \mathrm{ml}$ pepstatin, $1 \mathrm{mM} \mathrm{PMSF}$, and a cocktail of serine/threonine $P^{\prime}$ tse inhibitors. In other experiments, edelfosine (EMD), lysoPC (Sigma-Aldrich), fumonisin B1 (Sigma-Aldrich), 1-butanol (SigmaAldrich), 2-butanol (Sigma-Aldrich), and propranolol (EMD) were added at the concentrations indicated.

\section{Immunoblotting}

Cells were stimulated with LPS for the indicated times, washed twice with ice-cold PBS before scraping, and lysed with buffer $150 \mathrm{mM}$ Tris/ $\mathrm{HCl}$, $\mathrm{pH} 7.5,150 \mathrm{mM} \mathrm{NaCl}, 1 \%$ Triton X-100, $1 \%$ deoxycholate, 1 mM EGTA, $0.4 \mathrm{mM}$ EDTA, $2.5 \mathrm{\mu g} / \mathrm{ml}$ aprotinin, $2.5 \mathrm{\mu g} / \mathrm{ml}$ leupeptin, $1 \mathrm{mM}$ phenylmethanesulfonyl fluoride, and $0.2 \mathrm{mM} \mathrm{Na}_{3} \mathrm{VO}_{4}$ ). Where indicated, $20 \mu \mathrm{M}$ TAPI (EMD), an inhibitor of TACE, was added together with LPS. Equal amounts of protein lysates were resolved by SDS-PAGE and transferred to polyvinylidene difluoride membranes. Blots were blocked in 5\% nonfat dry milk in TBST buffer $(20 \mathrm{mM}$ Tris- $\mathrm{HCl}, 0.15 \mathrm{M} \mathrm{NaCl}$, and $0.1 \%$ Tween-20) and immunoblotted with anti-TNF $\alpha$ antibody (Abcam or Cayman Chemical). Signal was detected using a secondary antibody conjugated to horseradish peroxidase and incubation for 2 min with ECL reagent (GE Healthcare) according to the manufacturer's instructions. Blots were exposed to Hyperfilm ECL (GE Healthcare) and developed.

\section{Immunocytochemistry}

Cells were seeded at a density of $2.5 \times 10^{4}$ cells per well on poly-lysinecoated coverslips in 24-well plates and cultured. After treatment with $10 \mathrm{ng} / \mathrm{ml}$ LPS, cells were washed twice with cold PBS and fixed in $4 \%$ paraformaldehyde in $0.1 \mathrm{M}$ phosphate buffer, $\mathrm{pH} 7.4$, for 10 min at $25^{\circ} \mathrm{C}$. After two $5 \mathrm{~min}$ washes with PBS, pH 7.6, cells were permeabilized and blocked by blocking buffer containing $0.2 \%$ Triton X-100 and $1.5 \%$ horse serum in PBS. Cells were then incubated overnight at $4^{\circ} \mathrm{C}$ with FITC-labeled anti-mouse CD $11 \mathrm{~b}$ (GE Healthcare), anti-TNF $\alpha$ (Abcam), anti-CCT $\alpha$ (Santa Cruz Biotechnology, Inc.), anti-ERGIC-53 (Sigma-Aldrich), anti-K58 (Abcam), anti-MAC-1 (Abcam), or anti-IL-6 (Abcam). The next morning, the primary antibodies were washed three times for 5 min with TBS with $0.2 \%$ Triton X-100, and a 1:200 dilution in blocking buffer of Alexa 488- or Alexa 594conjugated secondary anti-rabbit Ig antibody (Invitrogen) was added to the cells, which were incubated for $1 \mathrm{~h}$ at $25^{\circ} \mathrm{C}$. After three final 5 -min washes with PBS, cells were mounted in mounting medium with DAPI (Invitrogen). Fluorescence microscopy was performed by the Scientific Imaging Shared Resource at St. Jude Children's Research Hospital using a microscope (E800; Nikon) equipped with $40 \times 0.95 \mathrm{NA}$ and $20 \times 0.50 \mathrm{NA}$ objectives (Nikon). The images were obtained using ProLong Gold Antifade Reagent (with DAPI; Invitrogen) and fluorochromes Alexa 594 and 488 (Invitrogen). The images were recorded with a camera (DMX1200; Nikon) and $\mathrm{ACT}$ acquisition software (Nikon) and prepared for publication using Photoshop CS2 (Adobe) for picture size and solution adjustment.

\section{Real-time qRT-PCR}

Real-time qRT-PCR was used to determine the relative expression levels of the Pcytla, Pldl, and Ceptl genes in wild-type macrophages. Total RNA was isolated using the RNAeasy Mini kit (QIAGEN) according to the manufacturer's instructions. Pelleted RNA was resuspended in nuclease-free water and digested with DNase I to remove contaminating genomic DNA. Total RNA $(0.5 \mathrm{\mu g})$ was reverse transcribed using random primers and SuperScript II RNase $\mathrm{H}^{-}$reverse transcription (Invitrogen). Real-time qPCR was performed with $10 \%$ of the reverse transcription product in a $30-\mu l$ reaction volume of Taqman Universal PCR master mixes (Applied Biosystems) using the 7300 sequence detection system and software version 1.2.1 (Applied Biosystems). Specific primers and probes are listed in Table S2 (available at http://www.jcb.org/cgi/content/full/jcb.200706152/DC1). The Taqman rodent glyceraldehyde-3-phosphate dehydrogenase (GAPDH) control reagent (Applied Biosystems) was the source of the primers and probes for quantifying the control GAPDH mRNA. All of the real-time valves were averaged and compared using the $C_{T}$ method, where the amount of target RNA $\left(2^{-\Delta \Delta C T}\right)$ was normalized to the endogenous GAPDH reference $\left(\Delta C_{T}\right)$ and related to the amount of target transcript in untreated control cells $\left(\Delta \Delta C_{T}\right)$, which was set as the calibrator at 1.0 .

\section{Mouse infection model}

Strain T4X of $S$. pneumoniae, a type 4 encapsulated, stable, bioluminescent derivative of clinical strain TIGR4, was grown as described previously (Orihuela et al., 2004). Wild-type and knock out mice were anesthetized with $2.5 \%$ isoflurane (Baxter Healthcare Corp) and infected intranasally with $10^{7}$ colony-forming units per $25 \mu$ of S. pneumoniae T4X. Mice were 
imaged for bioluminescence using the Ivis Imaging System (Caliper Life Sciences) to document differences in the course of disease at 24, 48, 72, and $96 \mathrm{~h}$ after infection as described previously (Orihuela et al., 2004). Lung was isolated just before death for histopathology analysis. Frozen sections were used for histochemistry with TNF $\alpha$ and MAC-1 (Abcam), and paraffin sections were used for hematoxylin and eosin and Gram's staining. All procedures were approved by the Animal Care and Use Committee of St. Jude Children's Research Hospital.

\section{Statistical analysis}

All data were reported as the mean \pm SE as calculated using GraphPad Prism 4 software (GraphPad Software). The unpaired student $t$ test was used to determine comparative significance. Results were considered significant at a p-value of $<0.05\left({ }^{*}\right)$ or $<0.01\left(^{* *}\right)$.

\section{Online supplemental material}

Fig. S1 illustrates the total production and cellular cytokine content of wildtype and $\mathrm{CCT} \alpha$-null cells after LPS stimulation. Fig. S2 shows the inhibition by TAPI on total production of TNF $\alpha$ but not IL-6. Fig. S3 illustrates the secretion of ApoE from wild-type and CCT $\alpha$-null cells. Fig. S4 characterizes the macrophage populations in mice, quantifies the protein content of macrophages, and illustrates the cellular distributions of $\mathrm{CCT} \alpha, \mathrm{CCT} \beta$, and TNF $\alpha$ in wild-type and knockout macrophages. Fig. S5 illustrates the PtdEtn, PtdCho, and SM levels in cells treated with LPS \pm fumonesin B 1 ; the lipid gene expression levels quantified by qRT-PCR after LPS stimulation of macrophages; and the DAG levels in knockout macrophages. Table S1 lists the lipid genes up-regulated in LPS-treated macrophages as determined by Affymetrix microarray analysis. Table S2 lists the qRT-PCR primers and probes used to obtain the data in Fig. S5 E. Online supplemental material is available at http://www.jcb.org/cgi/content/full/jcb.200706152/DC1

We thank Christopher Gunter, Christopher Sage, S. Hope Smith-Sielicki, and Matthew Frank for technical assistance, and Charles Rock for critical reading of the manuscript.

The research was supported by National Institutes of Health grant GM45737 (to S. Jackowski), Spanish Ministry of Education grant SAF20041698 (to E. Claro and A. Andreolotti), Cancer Center (CORE) Support grant CA 21765 , and the American Lebanese Syrian Associated Charities.

Submitted: 22 June 2007

Accepted: 19 May 2008

\section{References}

Altan-Bonnet, N., R. Sougrat, and J. Lippincott-Schwartz. 2004. Molecular basis for Golgi maintenance and biogenesis. Curr. Opin. Cell Biol. 16:364-372.

Altan-Bonnet, N., R. Sougrat, W. Liu, E.L. Snapp, T. Ward, and J. LippincottSchwartz. 2006. Golgi inheritance in mammalian cells is mediated through endoplasmic reticulum export activities. Mol. Biol. Cell. 17:990-1005.

Andrei, C., P. Margiocco, A. Poggi, L.V. Lotti, M.R. Torrisi, and A. Rubartelli. 2004. Phospholipases $C$ and $A_{2}$ control lysosome-mediated IL- $1 \beta$ secretion: Implications for inflammatory processes. Proc. Natl. Acad. Sci. USA. 101:9745-9750.

Attard, G.S., R.H. Templer, W.S. Smith, A.N. Hunt, and S. Jackowski. 2000. Modulation of CTP:phosphocholine cytidylyltransferase by membrane curvature elastic stress. Proc. Natl. Acad. Sci. USA. 97:9032-9036.

Baburina, I., and S. Jackowski. 1998. Apoptosis triggered by 1-O-Octadecyl2-O-methyl-rac-glycero-3-phosphocholine is prevented by increased expression of CTP:phosphocholine cytidylyltransferase. J. Biol. Chem. 273:2169-2173.

Baburina, I., and S. Jackowski. 1999. Cellular responses to excess phospholipid. J. Biol. Chem. 274:9400-9408.

Baron, C.L., and V. Malhotra. 2002. Role of diacylglycerol in PKD recruitment to the TGN and protein transport to the plasma membrane. Science. 295:325-328.

Bi, K., M. Roth, and N.T. Ktistakis. 1997. Phosphatidic acid formation by phospholipase D is required for transport from endoplasmic reticulum to the Golgi complex. Curr. Biol. 7:301-307.

Bligh, E.G., and W.J. Dyer. 1959. A rapid method of total lipid extraction and purification. Can. J. Biochem. Physiol. 37:911-917.

Bloom, G.S., and T.A. Brashear. 1989. A novel 58-kDa protein associates with the Golgi apparatus and microtubules. J. Biol. Chem. 264:16083-16092.

Boggs, K.P., C.O. Rock, and S. Jackowski. 1995a. Lysophosphatidylcholine and 1-O-octadecyl-2-O-methyl-rac-glycero-3-phosphocholine inhibit the
CDP-choline pathway of phosphatidylcholine synthesis at the CTP:phosphocholine cytidylyltransferase step. J. Biol. Chem. 270:7757-7764.

Boggs, K.P., C.O. Rock, and S. Jackowski. 1995b. Lysophosphatidylcholine attenuates the cytotoxic effects of the antineoplastic phospholipid 1-Ooctadecyl-2-O-methyl-rac-glycero-3-phosphocholine. J. Biol. Chem. 270:11612-11618

Bradford, M.M. 1976. A rapid and sensitive method for quantitation of microgram quantities of protein utilizing the principle of protein-dye binding. Anal. Biochem. 72:248-254.

Carrasco, S., and I. Merida. 2007. Diacylglycerol, when simplicity becomes complex. Trends Biochem. Sci. 32:27-36.

Clausen, B.E., C. Burkhardt, W. Reith, R. Renkawitz, and I. Forster. 1999. Conditional gene targeting in macrophages and granulocytes using LysMcre mice. Transgenic Res. 8:265-277.

Cleves, A.E., T.P. McGee, E.A. Whitters, K.M. Champion, J.R. Aitken, W. Dowhan, M. Goebl, and V.A. Bankaitis. 1991. Mutations in the CDPcholine pathway for phospholipid biosynthesis bypass the requirement for an essential phospholipid transfer protein. Cell. 64:789-800.

Corda, D., C.C. Hidalgo, M. Bonazzi, A. Luini, and S. Spano. 2002. Molecular aspects of membrane fission in the secretory pathway. Cell. Mol. Life Sci. 59:1819-1832

Corda, D., A. Colanzi, and A. Luini. 2006. The multiple activities of CtBP/BARS proteins: the Golgi view. Trends Cell Biol. 16:167-173.

Cornell, R.B., and I.C. Northwood. 2000. Regulation of CTP:phosphocholine cytidylyltransferase by amphitropism and relocalization. Trends Biochem. Sci. 25:441-447.

Cornell, R.B., and S.G. Taneva. 2006. Amphipathic helices as mediators of the membrane interaction of amphitropic proteins, and as modulators of bilayer physical properties. Curr. Protein Pept. Sci. 7:539-552.

Corrotte, M., S. Chasserot-Golaz, P. Huang, G. Du, N.T. Ktistakis, M.A. Frohman, N. Vitale, M.F. Bader, and N.J. Grant. 2006. Dynamics and function of phospholipase D and phosphatidic acid during phagocytosis. Traffic. 7:365-377.

Crowe, P.D., B.N. Walter, K.M. Mohler, C. Otten-Evans, R.A. Black, and C.F. Ware. 1995. A metalloprotease inhibitor blocks shedding of the $80-\mathrm{kD}$ TNF receptor and TNF processing in T lymphocytes. J. Exp. Med. 181:1205-1210.

Cui, Z., and M. Houweling. 2002. Phosphatidylcholine and cell death. Biochim. Biophys. Acta. 1585:87-96.

Devries-Seimon, T., Y. Li, P.M. Yao, E. Stone, Y. Wang, R.J. Davis, R. Flavell, and I. Tabas. 2005. Cholesterol-induced macrophage apoptosis requires ER stress pathways and engagement of the type A scavenger receptor. J. Cell Biol. 171:61-73.

Esko, J.D., M. Nishijima, and C.R.H. Raetz. 1982. Animal cells dependent on exogenous phosphatidylcholine for membrane biogenesis. Proc. Natl. Acad. Sci. USA. 79:1698-1702.

Fagone, P., R. Sriburi, C. Ward-Chapman, M. Frank, J. Wang, C. Gunter, J.W. Brewer, and S. Jackowski. 2007. Phospholipid biosynthesis program underlying membrane expansion during B-lymphocyte differentiation. J. Biol. Chem. 282:7591-7605.

Freyberg, Z., A. Siddhanta, and D. Shields. 2003. "Slip, sliding away": phospholipase D and the Golgi apparatus. Trends Cell Biol. 13:540-546.

Gafencu, A.V., M.R. Robciuc, E. Fuior, V.I. Zannis, D. Kardassis, and M. Simionescu. 2007. Inflammatory signaling pathways regulating ApoE gene expression in macrophages. J. Biol. Chem. 282:21776-21785.

Gearing, A.J., P. Beckett, M. Christodoulou, M. Churchill, J. Clements, A.H. Davidson, A.H. Drummond, W.A. Galloway, R. Gilbert, and J.L. Gordon. 1994. Processing of tumour necrosis factor-alpha precursor by metalloproteinases. Nature. 370:555-557.

Gearing, A.J., P. Beckett, M. Christodoulou, M. Churchill, J.M. Clements, M. Crimmin, A.H. Davidson, A.H. Drummond, W.A. Galloway, and R. Gilbert. 1995. Matrix metalloproteinases and processing of pro-TNFalpha. J. Leukoc. Biol. 57:774-777.

Gilchrist, A., C.E. Au, J. Hiding, A.W. Bell, J. Fernandez-Rodriguez, S. Lesimple, H. Nagaya, L. Roy, S.J. Gosline, M. Hallett, et al. 2006. Quantitative proteomics analysis of the secretory pathway. Cell. 127:1265-1281.

Girotti, M., J.H. Evans, D. Burke, and C.C. Leslie. 2004. Cytosolic phospholipase A2 translocates to forming phagosomes during zymosan phagocytosis in mouse macrophages. J. Biol. Chem. 279:19113-19121.

Gunter, C., M. Frank, Y. Tian, K.G. Murti, J.E. Rehg, and S. Jackowski. 2007. Probucol therapy overcomes the reproductive defect in CTP:phosphocholine cytidylyltransferase $\beta 2$ knockout mice. Biochim. Biophys. Acta. 1771:845-852.

Gupta, T., and T. Schüpbach. 2003. Cct1, a phosphatidylcholine biosynthesis enzyme, is required for Drosophila oogenesis and ovarian morphogenesis. Development. 130:6075-6087.

Gusarova, V., J. Seo, M.L. Sullivan, S.C. Watkins, J.L. Brodsky, and E.A. Fisher. 2007. Golgi-associated maturation of very low density lipoproteins involves 
conformational changes in apolipoprotein B, but is not dependent on apolipoprotein E. J. Biol. Chem. 282:19453-19462.

Henneberry, A.L., T.A. Lagace, N.D. Ridgway, and C.R. McMaster. 2001 Phosphatidylcholine synthesis influences the diacylglycerol homeostasis required for Sec14p-dependent Golgi function and cell growth. Mol. Biol. Cell. 12:511-520.

Henneberry, A.L., M.M. Wright, and C.R. McMaster. 2002. The major sites of cellular phospholipid synthesis and molecular determinants of fatty acid and lipid head group specificity. Mol. Biol. Cell. 13:3148-3161.

Huijbregts, R.P., L. Topalof, and V.A. Bankaitis. 2000. Lipid metabolism and regulation of membrane trafficking. Traffic. 1:195-202.

Iyer, S.S., J.A. Barton, S. Bourgoin, and D.J. Kusner. 2004. Phospholipases D1 and D2 coordinately regulate macrophage phagocytosis. J. Immunol. 173:2615-2623.

Jackowski, S. 1994. Coordination of membrane phospholipid synthesis with the cell cycle. J. Biol. Chem. 269:3858-3867.

Jackowski, S. 1996. Cell cycle regulation of membrane phospholipid metabolism. J. Biol. Chem. 271:20219-20222.

Jackowski, S., and P. Fagone. 2005. CTP: Phosphocholine cytidylyltransferase: paving the way from gene to membrane. J. Biol. Chem. 280:853-856.

Jackowski, S., J.E. Rehg, Y.-M. Zhang, J. Wang, K. Miller, P. Jackson, and M.A. Karim. 2004. Disruption of CCT $\beta 2$ expression leads to gonadal dysfunction. Mol. Cell. Biol. 24:4720-4733.

Jacobs, R.L., C. Devlin, I. Tabas, and D.E. Vance. 2004. Targeted deletion of hepatic CTP:phosphocholine cytidylyltransferase a in mice decreases plasma high density and very low density lipoproteins. J. Biol. Chem. 279:47402-47410.

Jenkins, G.M., and M.A. Frohman. 2005. Phospholipase D: a lipid centric review. Cell. Mol. Life Sci. 62:2305-2316.

Karim, M., P. Jackson, and S. Jackowski. 2003. Gene structure, expression and identification of a new CTP:phosphocholine cytidylyltransferase $\beta$ isoform. Biochim. Biophys. Acta. 1633:1-12.

Kearns, B.G., T.P. McGee, P. Mayinger, A. Gedvilaite, S.E. Phillips, S. Kagiwada, and V.A. Bankaitis. 1997. Essential role for diacylglycerol in protein transport from the yeast Golgi complex. Nature. 387:101-105.

Kent, C. 1997. CTP:phosphocholine cytidylyltransferase. Biochim. Biophys. Acta. 1348:79-90.

Lev, S. 2006. Lipid homoeostasis and Golgi secretory function. Biochem. Soc. Trans. 34:363-366.

Lindmo, K., and H. Stenmark. 2006. Regulation of membrane traffic by phosphoinositide 3-kinases. J. Cell Sci. 119:605-614.

Litvak, V., N. Dahan, S. Ramachandran, H. Sabanay, and S. Lev. 2005. Maintenance of the diacylglycerol level in the Golgi apparatus by the Nir2 protein is critical for Golgi secretory function. Nat. Cell Biol. 7:225-234.

Luche, M.M., C.O. Rock, and S. Jackowski. 1993. Expression of rat CTP:phosphocholine cytidylyltransferase in insect cells using a baculovirus vector. Arch. Biochem. Biophys. 301:114-118.

Lucic, D., Z.H. Huang, D. Gu, P.V. Subbaiah, and T. Mazzone. 2007. Cellular sphingolipids regulate macrophage apolipoprotein E secretion. Biochemistry. 46:11196-11204.

Lykidis, A., and S. Jackowski. 2001. Regulation of mammalian cell membrane biosynthesis. Prog. Nucleic Acid Res. Mol. Biol. 65:361-393.

Lykidis, A., K.G. Murti, and S. Jackowski. 1998. Cloning and characterization of a second human CTP:phosphocholine cytidylyltransferase. J. Biol. Chem. 273:14022-14029.

Lykidis, A., I. Baburina, and S. Jackowski. 1999. Distribution of CTP:phosphocholine cytidylyltransferase (CCT) isoforms. Identification of a new CCT $\beta$ splice variant. J. Biol. Chem. 274:26992-27001.

Lykidis, A., P. Jackson, and S. Jackowski. 2001. Lipid activation of CTP:phosphocholine cytidylyltransferase $\alpha$ : Characterization and identification of a second activation domain. Biochemistry. 40:494-503.

Mbebi, C., J.L. Gonzalez de Aguilar, V. See, L. Dupuis, N. Frossard, L. Mercken, L. Pradier, Y. Larmet, and J.P. Loeffler. 2005. Antibody-bound beta-amyloid precursor protein stimulates the production of tumor necrosis factor-alpha and monocyte chemoattractant protein-1 by cortical neurons. Neurobiol. Dis. 19:129-141.

Munro, S. 2005. The Golgi apparatus: defining the identity of Golgi membranes. Curr. Opin. Cell Biol. 17:395-401.

Orihuela, C.J., G. Gao, K.P. Francis, J. Yu, and E.I. Tuomanen. 2004. Tissuespecific contributions of pneumococcal virulence factors to pathogenesis. J. Infect. Dis. 190:1661-1669.

Patton-Vogt, J.L., P. Griac, A. Sreenivas, V. Bruno, S. Dowd, M.J. Swede, and S.A. Henry. 1997. Role of the yeast phosphatidylinositol/phosphatidylcholine transfer protein (Sec14p) in phosphatidylcholine turnover and INO1 regulation. J. Biol. Chem. 272:20873-20883.

Preiss, J.E., C.R. Loomis, R.M. Bell, and J.E. Niedel. 1987. Quantitative measurement of sn-1,2-diacylglycerols. Methods Enzymol. 141:294-300.
Ridsdale, R., and M. Post. 2004. Surfactant lipid synthesis and lamellar body formation in glycogen-laden type II cells. Am. J. Physiol. Lung Cell. Mol. Physiol. 287:L743-L751.

Roth, M.G. 1999. Lipid regulators of membrane traffic through the Golgi complex. Trends Cell Biol. 9:174-179.

Shell, S.A., C. Hesse, S.M. Morris Jr., and C. Milcarek. 2005. Elevated levels of the 64-kDa cleavage stimulatory factor (CstF-64) in lipopolysaccharidestimulated macrophages influence gene expression and induce alternative poly(A) site selection. J. Biol. Chem. 280:39950-39961.

Shemesh, T., A. Luini, V. Malhotra, K.N. Burger, and M.M. Kozlov. 2003. Prefission constriction of Golgi tubular carriers driven by local lipid metabolism: a theoretical model. Biophys. J. 85:3813-3827.

Sriburi, R., S. Jackowski, K. Mori, and J.W. Brewer. 2004. XBP1: a link between the unfolded protein response, lipid biosynthesis, and biogenesis of the endoplasmic reticulum. J. Cell Biol. 167:35-41.

Sriburi, R., H. Bommiasamy, G.L. Buldak, G.R. Robbins, M. Frank, S. Jackowski, and J.W. Brewer. 2007. Coordinate regulation of phospholipid biosynthesis and secretory pathway gene expression in XBP-1(S)-induced endoplasmic reticulum biogenesis. J. Biol. Chem. 282:7024-7034.

Tang, W., A. Walsh, and I. Tabas. 1999. Macrophage-targeted CTP: phosphocholine cytidylyltransferase (1-314) transgenic mice. Biochim. Biophys. Acta. 1437:301-316.

Tian, Y., R. Zhou, J.E. Rehg, and S. Jackowski. 2007. Role of phosphocholine cytidylyltransferase $\alpha$ in lung development. Mol. Cell. Biol. 27:975-982.

Trotter, P.J., and D.R. Voelker. 1994. Lipid transport processes in eukaryotic cells. Biochim. Biophys. Acta. 1213:241-262.

Wang, L., S. Magdaleno, I. Tabas, and S. Jackowski. 2005. Early embryonic lethality in mice with targeted deletion of the CTP:phosphocholine cytidylyltransferase $\alpha$ gene (Pcyt1a). Mol. Cell. Biol. 25:3357-3363.

Weber, U., C. Eroglu, and M. Mlodzik. 2003. Phospholipid membrane composition affects EGF receptor and notch signaling through effects on endocytosis during Drosophila development. Dev. Cell. 5:559-570.

Weigert, R., M.G. Silletta, S. Spano, G. Turacchio, C. Cericola, A. Colanzi, S. Senatore, R. Mancini, E.V. Polishchuk, M. Salmona, et al. 1999. CtBP/ BARS induces fission of Golgi membranes by acylating lysophosphatidic acid. Nature. 402:429-433.

Wenk, M.R., and C.P. De. 2004. Protein-lipid interactions and phosphoinositide metabolism in membrane traffic: insights from vesicle recycling in nerve terminals. Proc. Natl. Acad. Sci. USA. 101:8262-8269.

Yeung, T., B. Ozdamar, P. Paroutis, and S. Grinstein. 2006. Lipid metabolism and dynamics during phagocytosis. Curr. Opin. Cell Biol. 18:429-437.

Zhang, D., W. Tang, P.M. Yao, C. Yang, B. Xie, S. Jackowski, and I. Tabas. 2000. Macrophages deficient in CTP:phosphocholine cytidylyltransferase- $\alpha$ are viable under normal culture conditions but are highly susceptible to free cholesterol-induced death. Molecular genetic evidence that the induction of phosphatidylcholine biosynthesis in free cholesterol-loaded macrophages is an adaptive response. J. Biol. Chem. 275:35368-35376. 